\title{
OCORRÊNCIA DE ISOLADOS DE Botrytis cinerea PERS. EX FR. RESISTENTES A BENOMYL EM MORANGOS (q NO ESTADO DE SÃO PAULO
}

\author{
HELOISA MARIA CABRINI
}

Orientador : Prof. Dr. HIROSHI KIMATI

\begin{abstract}
Dissertação apresentada à Escola Superior de Agricultura "Luiz de Queiroz", da Universidade de São Paulo, para obtenção do título de Mestre em Agronomia - Área de Concentração: Fitopatologia.
\end{abstract}

PIRACICABA

Estado de São Paulo - Brasil

Junho, 1985 
meus pais e meus irmãos, DEDICO 
AGRADEC IMENTOS

A autora expressa seus agradecimentos:

Ao Professor Dr. Hiroshi Kimati, pela segura orientação, apoïo, estímulo e amizade durante a realização e redação deste trabalho. Ao Departamento de Fitopatologia da Escola Superior de Agricultura "Luiz de Queiroz", pela possibilidade de participação no Curso de Pós-Graduação e realização do presente trabalho.

Aos Professores do Departamento de Fitopatologiada ESALQ, pelos ensinamentos e amizade.

Ao Professor Dr. Keigo Minami, pelo fornecimento de morango doente do campo experimental do Setor de Horticultura da ESALQ, pela colaboração e estímulo durante o desenvolvimento deste trabalho.

Ao Dr. Juarez Betti do Instituto Agronômico de Campinas (IAC), pelo envio de morango doente.

Aos colegas do Curso de Pós-Graduação, pela amizade e estímulo.

Aos funcionärios do Departamento de Fitopatologia da ESALQ, pela colaboração.

À Fundação de Amparo à Pesquisa do Estado de São Paulo (FAPESP), pela concessão da bolsa de estudos.

A todos que direta ou indiretamente colaboraram na realização deste trabalho. 
INDTCE

pāgina

IISTA DE TABELAS $\ldots \ldots \ldots \ldots \ldots \ldots \ldots \ldots \ldots \ldots \ldots \ldots \ldots \ldots \ldots \ldots \ldots \ldots \ldots$

RESUMO $\ldots \ldots \ldots \ldots \ldots \ldots \ldots \ldots \ldots \ldots \ldots \ldots \ldots \ldots \ldots \ldots \ldots \ldots \ldots \ldots \ldots \ldots \ldots \ldots$

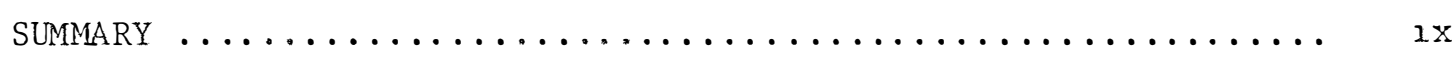

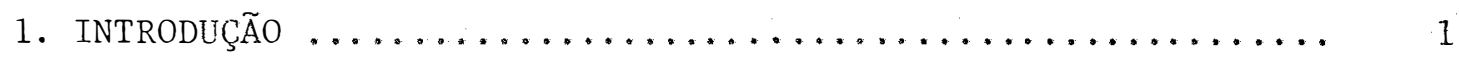

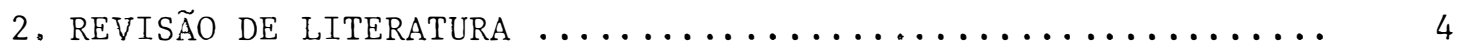

2.1. Resistência de Fungos a Fungicidas .............. 4

2.2. Adaptabilidade dos Mutantes Resistentes ........... 12

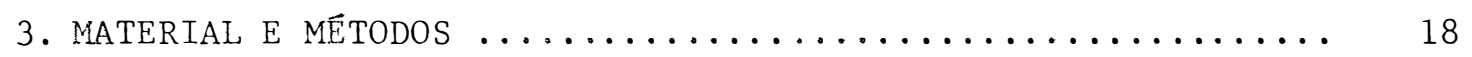

3.1. Isolamento $\ldots \ldots \ldots \ldots \ldots \ldots \ldots \ldots \ldots \ldots \ldots \ldots \ldots$

3.2. Técnica de Isolamento $\ldots \ldots \ldots \ldots \ldots \ldots \ldots \ldots \ldots \ldots$

3.3. Preservação do Fungo ..................... 20

3.4. Preparo dos Meios de Cultura com Fungicidas ......... 21

3.5. Experimentos Realizados .................... 21

3.5.1. Frequência de isolados de Botrytis cinerea resistentes ao fungicida benomyl, em cond $\underline{i}$

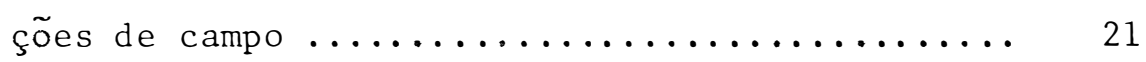

3.5.2. Resposta in vitro de isolados de Botrytis cinerea sensiveis e resistentes ao benomỳ 1 , a doses crescentes do fungicida ..........

3.5.3. Nível de resistência dos mutantes ao benomy $1 \ldots \ldots \ldots \ldots \ldots \ldots \ldots \ldots \ldots$

3.5.4. Avaliação da esporulação de um isolado de Botrytis cinerea sensivel e de quatro resistentes, em meio de cultura isento de

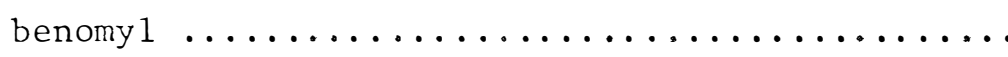


3.5.5. Sensibilidade colateral in vitro de quatro isolados de Botrytis cinerea resistentes e um sensivel ao benomyl, a quatro fungicidas ..... 26

3.5.6. Competição in vitro entre um isolado de Botrytis cinerea sensivel e outro resisten

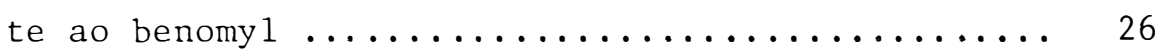

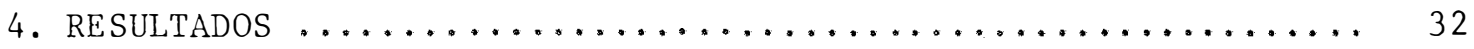

4.1. Frequência de Isolados de Botrytis cinerea Resistentes ao Fungicida Benomyl, em Condições de Campo ..... 32

4.2. Resposta in vitro de Isolados de Botrytis cinerea Sensiveis e Resistentes ao Benomy1, a Doses Crescentes do Fungicida ............................ 34

4.3. Nível de Resistência dos Mutantes ao Benomyl ......... 36

4.4. Avaliação da Esporulação de Um Isolado de Botrytis cinerea Sensível e de Quatro Resistentes, em Meio de Cultura Isento de Benomyl ................. 38

4.5. Sensibilidade Colateral in vitro de Quatro Isolados de Botrytis cinerea Resistentes e Um Sensível ao Benomyl, a Quatro Fungicidas ................ 40

4.6. Competição in vitro entre Um Isolado de Botrytis cinerea Sensive1 e Outro Resistente ao Benomy $1 . . . . .445$

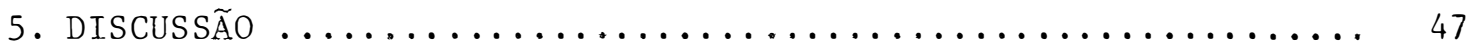

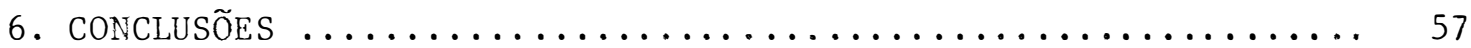

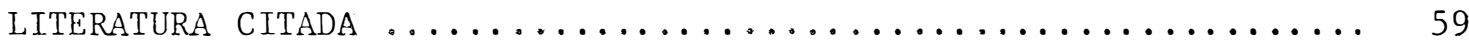


1 Relação dos isolados de Botmytis cinerea utilizados durante a execução do presente trabalho $\ldots \ldots \ldots \ldots \ldots \ldots$

2 Fungicidas utilizados nos experimentos $\ldots . . \ldots \ldots \ldots$

3 Procedência dos dois isolados de Botrytis cinerea utilizados para se fazer a suspensão de esporos ......

4 Frequência de isolados de Botrytis cinerea de morango resistentes a $100 \mathrm{ppm}$ de benomy $1 \ldots \ldots \ldots \ldots$

5 Crescimento micelial de sete isolados de Botrytis cinerea aos três dias de incubação, em meio de BDA contendo diferentes concentraçōes de benomyl ........

6 Crescimento micelial de cinco isolados de Botrytis cinerea aos quatro dias de incubação, em meio de cultura de BDA contendo diferentes concentrações de

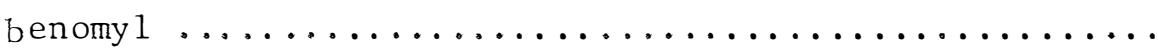

7 Capacidade de esporulação de quatro isolados benomyl-resistentes em comparaçăo com um benomyl-sensí vel de Botrytis cinerea, em meio de BDA ............

8 Crescimento micelial de cinco isolados de Botrytis cinerea aos quatro dias de incubação, em meio de cultura de BDA contendo diferentes concentrações de

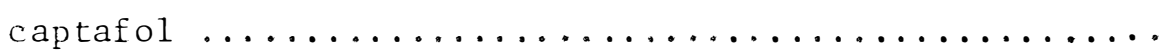


9 Crescimento micelial de cinco isolados de Botrytis cinerea aos quatro dias de incubação, em meio de cultura de BDA contendo diferentes concentrações de iprodione $\ldots \ldots \ldots \ldots \ldots \ldots \ldots \ldots \ldots \ldots \ldots \ldots \ldots \ldots \ldots \ldots \ldots \ldots$

10 Crescimento micelial de cinco isolados de Botrytis cinerea aos quatro dias de incubação, em meio de cultura de BDA contendo diferentes concentrações

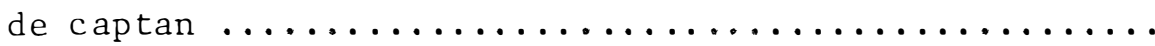

11 Crescimento micelial de cinco isolados de Botrytis cinerea aos quatro dias de incubação, em meio de cultura de BDA contendo diferentes concentrações de procymidone ........................... 44

12 Efeito da competição em meio de cultura na frequência relativa de isolados de Botmytis cinerea resis tente e sensivel ao fungicida benomy $1 . . . \ldots . . . .$. 
OCORR $\widehat{E} N C I A$ DE ISOLADOS DE Botrytis cinerea Pers. ex Fr. RESISTENTES A BENOMYL EM MORANGOS (Fragaria spp.) NO ESTADO DE SÃO PAULO

Heloisa Maria Cabrini Orientador: Prof.Dr. Hiroshi Kimati

RESUMO

Foram feitos levantamentos do agente do mofo cinzento de morangos, provenientes de Atibaia, Campinas, Piedade, Valinhos e Piracicaba (S.P.). Dos 52 isolados conseguidos, 12, procedentes de Atibaia, se mostraram resistentes a $100 \mu g / m 1$ de benomyl. Desses 12,4 , tes tados a $1000 \mu g$ de benomy $1 / \mathrm{ml}$, apresentaram alguin crescimento. Comparações in vitro desses 4 com 1 isolado sensível a benomyl evidenciaram que, de um modo geral, os resistentes esporulam e crescem menos do que o sensivel em meio de BDA. Comparações desses mesmos isolados em relação a sensibilidade aos fungicidas captafol, captan, iprodione e procymidone não evidenciaram diferenças muito marcantes entre os isolados resistentes, como um grupo, e o sensível. Todos os isolados testados foram altamente sensíveis ao procymidone e ao iprodione. 


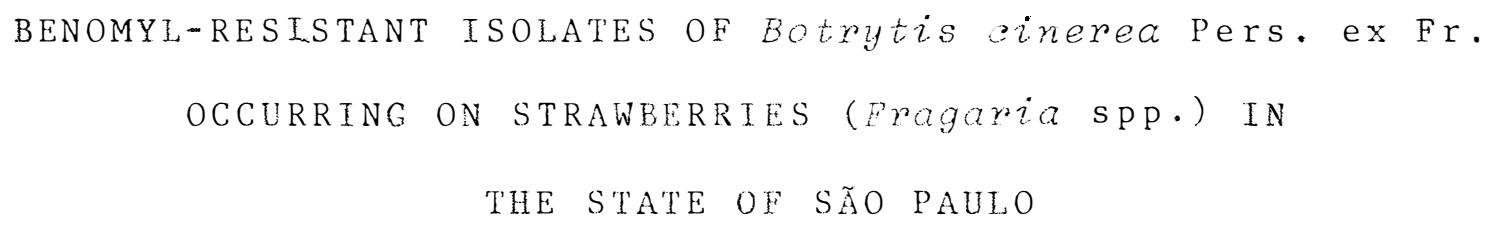

Heloisa Maria Cabrini Adviser: Prof.Dr. Hiroshi Kimati

SUMMARY

\begin{abstract}
Gray mold surveys were made, on strawberries from Atibaia, Campinas, Piedade, Valinhos and Piracicaba (S.P.). Of the 52 isolates obtained, 12, from Atibaia were resistant to $100 \mathrm{Hg} / \mathrm{ml}$ of benomyl. Of these 12,4 were tested at $1000 \mathrm{\mu g}$ of benomyl/ml, and showed some growth at this concentration. In vitro comparisons of these 4 isolates with benomyl-sensitive showed that, in general, the resistant ones sporulate and grow less than the benomyl-sensitive isolate in PDA medium. Comparisons of the same isolates in relation to sensitivity to the fungicides captafol, captan, iprodione and procymidone have not showed evident differences between resistant isolates, as a group, and the sensitive one. All isolates tested, irrespective of being benomyl-resistant or benomyl-sensitive, were highly sensitive to procymidone and iprodione.
\end{abstract}


1. INTRODUÇÃO

o plantio comercial de morango (Fragaria spp.) no Brasil foi iniciado hä cerca de 50 anos, tendo sido ampliado nos ültimos 25 anos. Atualmente é produzido nos estados de São Paulo (Atibaia, Valinhos, Piedade e Jundiaí), Minas Gerais (sul do estado) e Rio Grande do Sul (região de Pelotas), Entretanto, o cultivo de morango está sujeito a värios fatores que contribuem para a redução da produtividade, e dentre eles, a ocorrência de um nümero considerável de doenças se sobressai como um dos mais significativos.

Dentre essas doenças, o mofo cinzento (Botrytis cinerea Pers. ex Fr.) se destaca como uma das mais importantes (PESSANHA et alii, 1970). Trata-se de uma podridão do fruto bastante comum, ocorrendo em todas as regiōes do mundo onde se cultiva o morango, sempre determinando graves prejuízos, pela redução do produto comerciāvel (CARDoso, 1980).

Os frutos podem ser afetados em qualquer estägio de desen volvimento e tanto em condições de campo como pós-colheita. 
Os fatores ambientais que mais favorecem a incidéncia des sa doença são alta umidade e temperatura ao redor de $20^{\circ} \mathrm{C}$. Tais condições podem ser alcançadas durante o inverno no estado de São Paulo, prin cipalmente em relação a umidade relativa, pois, embora seja uma estação seca, são feitas irrigações quase que diariamente.

Um dos mais indicados métodos para o controle desta podri dão de fruto, constitui-se na aplicação de fungicidas; neste sentido, a partir de 1969, no estado de São Paulo, fungicidas convencionais como captan, que vinham sendo usados no controle dessa e outras doenças do mo rangueiro (mancha de micosferela, antracnose) foram gradualmente substituidos por benomyl, pertencente ao grupo dos benzimidazóis (REMIRO e KIMATI, 1974). Apesar da alta eficiência deste produto, alguns anos após a sua introdução, tem se observado falhas no controle do mofo cinzento e isso è atribuido ao desenvolvimento de linhagens de $B$. cinerea resistentes a esse fungicida.

o presente trabalho, visando obter maiores esclarecimentos em relação ao problema apontado acima, tem por objetivos:

1. Fazer um levantamento dos isolados de Botrytis cinerea resistentes e sensíveis ao benomyl, que ocorrem na cultura de morango, em condições de campo.

2. Determinar o nível de resistência dos mutantes.

3. Comparar a adaptabilidade in vitro entre isolados sensíveis e resistentes ao benomyl, atravês de parâmetros como: crescimento 
micelial, capacidade de esporulação e competição em meio de cultura.

4. Testar a ocorrência de sensibilidade colateral entre isolados benomyl-resistentes e benomyl-sensiveis, em relação aos fungicidas captafol, captan, iprodione e procymidone. 
2. REVISÃO DE LITERATURA

2.1. Resistência de Fungos a Fungicidas.

O fenômeno de perda de eficiência de drogas tem causado considerāvel dificuldade ao homem moderno em seus esforços para controlar organismos nocivos pelo uso de compostos tóxicos (GEORGOPOULOS, 1969). Realmente, desde os primórdios da quimioterapia se observou que, submetendo-se camundongos a pequenas doses de arsenicais, desenvolvia-se progressivamente uma resistência do protozoârio, não só em relação ao arsenical usado, mas tambëm a outros compostos de constituição quïmica semelhante e, no campo da medicina humana e veterinária, já há algum tem po se tem observado o fenômeno em bactérias com relação a sulfas e aos antibiöticos (BIER, 1965). Estudos intensivos têm sido feitos nesse cam po, principalmente com relação aos antibióticos e as revisões de BRYSON e SZYBALSKI (1955), SCHNITZER e GRUNBERG (1957), NEWTON (1965), GURGEL e AZEVEDO (1969) e WATANABE (1971) mostram a complexidade do assunto.

No campo da Agronomia, resistência de inse-
tos aos inseticidas datam de 1950, pouco depois do emprego de novos 
produtos orgânicos, tornando-se um problema no controle de pragas. Segundo BROWN (1961), até 1960 pelo menos 137 espécies de insetos, ácaros, etc., já tinham desenvolvido resistência a vārios grupos de inseticidas.

Familiarizados com tais experiências, eram surpreendentemente poucos os casos em que doenças de plantas, causadas por fungos, apresentassem problemas semelhantes e isso foi atribuido à natureza ines pecífica dos fungicidas usados no seu controle (GEORGOPOULOS, 1969). Assim, não houve preocupação neste sentido, por parte dos pesquisadores, até por volta de 1967 , jā que atẻ essa época, problemas de resistência de fungos a fungicidas, em condições de campo, se limitavam a apenas alguns relatos; dentre eles, se destacavam o de Penicillium digitatum e P. italicum em relação ao bifenil e ao ortofenilfenato de sódio; de Tilletia foetida em relação ao BHC, ao quintozene (ou PCNB) e ao tetracloronitroanisol; e de pyrenophora avenae em relação aos organomercuriais (KIMATI, 1978).

Em 1967 mesmo, GEORGOPOULOS e ZARACOVITIS (1967) concluiram que o aparecimento de formas resistentes, exceto em relação aos hidrocarbonetos, não apresentavam dificuldades, mas alertavam para o fato da resistência tornar-se mais comum na medida que os fungicidas alcançassem maior especificidade.

De fato, por volta de 1970 começaram a ser introduzidos em escala comercial, fungicidas seletivos, e resistência a tais fungicidas tem despertado muito maior interesse prático, na busca de soluções mais acertadas para o problema (KIRBY, 1972). 
Infelizmente, a descoberta cientifica que trouxe produtos químicos mais eficientes no controle de doenças, também propiciou o aparecimento de resistência. Esse paradoxo pode ser explicado em termos do modo de ação e mecanismos de resistência (DELP, 1980).

Os novos biocidas são tóxicos para determinados patógenos mas não afetam mamíferos, a cultura ou outros organismos, ou seja, eles têm um limitado espectro de toxicidade, de forma que os organismos a que se destinam podem frequentemente escapar da sua ação tóxica por uma simples mutação (UESUGI, 1978).

De acordo com DELP (1980), fungicidas convencionais são chamados inibidores multi-sitios, pois interferem em numerosos processos metabólicos vitais do patógeno, permitindo pouca chance para o desenvolvimento de resistência, jā que são requeridas múltiplas modificações no genoma do patógeno, para impedir a sua ação. Tais produtos como os ditiocarbamatos, os mercuriais, os compostos de cobre e outros, têm tido poucos problemas de resistência na prätica. Inibidores de sitios específicos, por outro lado, atuam em um ou dois locais metabólicos e resistência neste caso ê mais comum, desde que alteração em apenas um gene do fungo é suficiente para induzir uma modificação no sitio de ação. Assim, a aquisição de resistência pelo fungo, aos fungicidas protetores, implica em mutação poligênica, enquanto que a mutação em um ou poucos genes confere resistência a fungicidas mais específicos (seletivos) (UESUGI, 1978).

Devido ao modo de ação característico para cada tipo de fungicida, apesar do longo período durante o qual os convencionais tem 
estado em uso comercial, o nümero de casos de desenvolvimento de resistência é relativamente pequeno e de pouca importância prática (DEKKER, 1977). Em contraposição, atualmente, o nümero de relatos de fungos resistentes a fungicidas sistêmicos, mesmo levando-se em consideração somente a ocorrência em condições de campo, é bem grande e está em constante ascenção. Assim, jā se conhecem linhagens de fungos, antes sensíveis, que se tornaram resistentes a benomyl, tiofanato metílico, thiabendazol, ethirimol, dimethirimol, kasugamicina, entre outros (KIMATI, 1978) .

OGAWA et alii (1977) fizeram uma lista de somente 17 de 62 fungicidas orgânicos de contacto de uso geral, para os quais foi desenvolvida resistência, apesar de muitos deles estarem sendo utilizados há mais de 50 anos. Em contraste, uma ampla variedade de organismos tinham se tornado resistentes a 9 dos 10 sistêmicos em uso em 1977, embora o início da utilização do primeiro sistêmico, benomyl, tivesse sido hà menos de 10 anos.

De acordo com GEORGopoulos (1977), a aplicação de produtos quỉmicos em grandes äreas e anos seguidos tem o efeito de forçar mudanças evolucionárias e apressá-las, então, as drogas atuam como peneiras, separando e concentrando os mutantes resistentes. Quanto maior for a pressão de seleşão mais rápida será a mudança. o tempo durante o qual esta pressão é mantida é determinado pela persistência da droga, a frequência e o tipo de aplicação. O desenvolvimento de mutantes resistentes ocorre mais rapidamente no caso de produtos tóxicos inibidores de sitios especificos, sendo ue muitas vezes eles se tornam ineficientes 
dentro de 2-3 anos após sua primeira aplicação no campo. DOVAS et alii. (1976), comparando uma linhagem benomyl-sensível e uma benomyl-resistente de Cercospora beticola, observaram que a frequência de isolamento da linhagem resistente aumentou de $3,5 \%$ para $91,5 \%$, com apenas duas apiicações em um mês. WICKS (1974) constatou que depois de um período de 3 anos de uso regular de benomyl no controle da sarna da macieira, já foram observadas linhagens benomyl-resistentes de Venturia inaequalis, numa evidência de que resistēncia aos fungicidas benzimidazóis aparece apōs uso regular e exclusivo destes produtos.

Com drogas atuantes sobre múltiplos sitios, a perda da efetividade não sobrevêm com a mesma rapidez. Fungicidas organo-mercuriais vêm sendo usados desde 1920 e casos de resistência a estes compostos só foram observados a partir de 1966, em Pyrenophora avenae (SHERIDAN et alii, 1968). Somente após 9 anos de uso intensivo de dodine é que surgiram os primeiros relatos de linhagens resistentes em Venturia inaequalis (SZKOLNIK e GILPATRICK, 1969).

Nos ültimos anos, numerosos casos de aquisição de resistência têm sido registrados de muitas partes do mundo, principalmente em relação aos compostos benzimidazóis e tiofanatos (DEKKER, 1977). Realmente, dentre os Eungicidas sistêmicos, o grupo dos benzimidazóis são os que apresentam mais dramaticamente, sérios problemas de resistência (DEtu, 1980). Juntamente com os tiofanatos, eles são, sem dúvida, os compostos mais amplamente conhecidos, devido às suas excelentes propriedades sistêmicas e sua grande eficiência no controle de importantes doen ças de plantas; mas, infelizmente, também causam desapontamento quando 
problemas de resistência se desenvolvem no fungo que pretendem controlar (DAVIDSE, 1982). Esse grupo de fungicidas envolve casos mais frequentes de resistência entre os fungos Botrytis cinerea, Cereosporaspp., oídios, Venturia inaequalis, Verticillium spp. e Penicilizum spp.(KIMATI, 1978).

Deve-se acrescentar aqui a afirmação de DELP (1980), segundo o qual, até 1979, resistência aos compostos benzimidazóis foi encontrada em fungos pertencentes a 16 gêneros diferentes.

Frequentemente a resistência a fungicidas é de um alto ní vel. Em experimentos realizados por BOLLEN e SCHOLTEN (1971), onde se utilizou benomyl para o controle de Botrytis cinerea em viveiro de ciclamem, a aplicação deste fungicida foi satisfatória por vārias semanas; contudo, após curto período de uso, a eficiência do produto decaiu e das plantas doentes puderam ser isoladas linhagens do fungo que resistiram a concentrações muito mais altas de benomyl do que o tipo selvagem. Mesmo a 1000ppm do produto não houve uma completa inibição no crescimento, enquanto que o tipo selvagem foi eliminado a $0,5 \mathrm{ppm}$ de benomyl no meio. As linhagens resistentes mostraram resistência cruzada em relação a thia bendazol, fuberidazol e tiofanato metílico.

Em condiçóes naturais foram obtidos isolados de Botrytis cinerea resistentes a benomyl em sementeiro de alface e tomate, e que tambëm apresentaram resistência cruzada a meti1-tiofanato, thiabendazol e BAS 3460 F (MILLER e FLETCHER, 1974).

Outros autores têm relatado a aquisição de resistência de B. cinerea em relação aos compostos benzimidazóis (DEkKER, 1976; 
FLETCHER e GRIFFIN, 1981; PEPIN e Mac PHERSON, 1982).

Segundo IIDA (1975), isolados de Venturia inaequatis de pomares não tratados foram inibidos a concentrações de 10ppm de tiofanato metîlico; em contraste, isolados provenientes de pomares tratados suportaram atê $1000 \mathrm{ppm}$.

Em moranguinhos tratados com benomyl, foram isoladas formas resistentes de Mycosphaeretra fragamiae que suportaram até 100ppm da droga, enquanto a forma selvagem, 1 ppm (REMIRO e KIMATI, 1974), como tambëm foram constatadas duas classes de linhagens resistentes a este fungicida em penicitlium digitatum e P. italicum, as quais mostraram resistência cruzada em relação a tiof anato metílico (KURAMoTo, 1976). Resistência cruzada em relação a tiofanato metílico e thiabendazol tambëm foi encontrada em uma linhagem de $P$. exponsum resistente a benomyl, isolada de peras que tinham sido tratadas com este fungicida (WICKS, 1977).

De una casa de vegetação de pepino da Holanda, onde benomyl tinha sido aplicado para controlar oídio, foi obtida uma linhagem de Sphaerotheca fuziginea que, em teste de disco de folha, tolerou concentrações de benomyl de 100 a 1000 vezes mais elevadas do que aquela su portada pela linhagem sensỉvel do fungo (DEKKER, 1977).

Mais recentemente, for am introduzidos comercialmente os fungicidas dicarboximidas (dichlozoline, iprodione, procymidone, vinclozolin), como substitutos dos benzimidazóis, onde o controle de doenças de plantas já não se mostrava satisfatório devido à presença de linhagens benzimidazöis-resistentes. Assim, os dicarboximidas começaram a 
ser amplamente empregados para controlar doenças causadas por patögenos taxonômicamente relacionados como Sclerotinia, Monilinia e Botrytis, sen do particularmente eficientes contra mofo cinzento da uva, morango e tomate (causados por Botrytis cinerea) e doenças de podridão parda do fruto (causadas por Moni iinia spp.) (BEEVER e BYRDE, 1982).

Linhagens de fungos resistentes a esse grupo de fungicidas, inicialmente eram de ocorrência ocasional e não causavam maiores problemas; entretanto, recentemente tem sido relatadas falhas na eficiência destes produtos no controle de doenças, que foram associadas à presença de formas resistentes (BEEVER e BYRDE, 1982).

Os mutantes de fungos resistentes aos dicarboximidas apre sentam geralmente resistência cruzıda em relação aos fungicidas do grupo dos hidrocarbonetos aromáticos. Neste sentido, BEEVER e BRIEN (1983), constataram o desenvolvimento de linhagens de Botrytis cinerea resistentes a iprodione que mostraram resistêxcia cruzada em relação a dichlozoline, procymidone, vinclozolin e dicloran. Tal fato tambëm foi observado por HARTILL et alii (1983), onde os mutantes de $B$. cinerea além des tes produtos, tambëm apresentaram resistência cruzada em relação a quintozene e a maioria foi tambën resistente aos fungicidas benzimidazóis.

o desenvolvimento de linhagens de $B$. cinerea resistentes aos fungicidas dicarboximidas, tanto em condiçöes naturais, como in vitro, tem sido relatado por outros pesquisadores (KATAN, 1981; HISADA et alii, 1981; GULLINO e GARIBALDI, 1981; PANAGIOTAKU e MALATHRAKIS, 1981; FLETCHER e GRIFFIN, 1981; KATAN, 1982). 
2:2. Adaptabilidade dos Mutantes Resistentes.

Normalmente, linhagens resistentes surgem espontaneamente na população de sensíveis (DEKKER, 1977), em pequeno número, provavelmente menos do que 1 propágulo em $10^{8}$. Desde que essas linhagens resistentes raramente têm uma vantagem adaptativa sobre as formas selvagens, elas permanecem em níveis indetectáveis. Mas quando um agente de controle de doença seletivamente reduz ou elimina as populações selvagens sensiveis, formas resistentes que têm razoāvel adaptabilidade e são patogênicas aumentam na população (DELP, 1980). Enquanto a porcentagem de indivíduos resistentes for baixa, não haverä nenhum decrēscimo detectävel na eficiência do fungicida. Falhas no controle de doenças apenas ocorrerão quando, sob o efeito seletivo do fungicida, uma parte subs tancial da população de patógenos se tornar resistente (DEKKER, 1981). Mas a ocorrência ou não de tal fato depende de värios fatores, como as propriedades dos mutantes resistentes, o tipo de fungicida utilizado, o tipo de doença, a persistência e método usual do fungicida e as condições ambientais (DEKKER, 1977; 1981). Assim, o uso sucessivo de um fungicida ou de fungicidas pertencentes a um ünico grupo de resistência cru zada pode promover o desenvolvimento de resistência, sendo igualmente importantes a taxa de crescimento e reprodução do organismo em questão. Fungos que crescem rapidamente como Botrutis e oidio frequentemente causam problemas de resistência na prática (UESUGI, 1978).

Pelo exposto acima, $\vec{e}$ evidente que a adaptabilidade de mutantes resistentes a fungicidas, comparada àquela da linhagem selvagem, 
é de suprema importância para o estabelecimento de uma população de patógenos resistentes. Adaptabilidade è um conceito comparativo: um organismo é mais ou menos adaptável do que outro sob condições in vitro, em viveiro de plantas ou no campo. Parâmetros de adaptabilidade in vitro são: germinação de esporos, crescimento do micélio em agar ou em meio lí quido e esporulação em meio de agar. Parâmetros de adaptabilidade sobre a planta hospedeira são: a possibilidade de infecção, a velocidade de colonização do tecido do hospedeiro e o grau de esporulação. Linhagens com adaptabilidade mais elevada são mais competitivas (DEKKER, 1982a).

Se os individuos apresentarem um grau de adaptabilidade igual ou não muito menor do que aquele do patógeno sensível, uma população resistente ao fungicida poderā se desenvolver, mesmo se a pressão de seleção for somente moderada ou baixa. Por outro lado, a aquisição de resistência também pode estar associada com decréscimo de adaptabilidade; em tais casos, quanto maior a diferença da linhagem resistente em relação à sensível, mais dificultado serä o desenvolvimento de uma população de patógenos resistentes, podendo haver um atraso ou mesmo um impedimento do seu estabelecimento (DEKKER, 1981; 1982a).

Os relatos de literatura descrevem uma certa diversidade no comportamento dos isolados das värias espécies de fungos fitopatogênicos, em relação aos produtos químicos usados no seu controle. Assim, enquanto um isolado de Venturia inaequalis que adquiriu resistência ao antibiótico antimicina-A por irradiação U.V., perdeu completamente sua patogenicidade (LEBEN et alii, 1955), isolados de $V$. pirina resistentes 
a carbendazim foram todos patogênicos, desenvolvendo lesões

típicas (SHABI e KATAN, 1979).

A população de mutantes resistentes pode atingir altos ni veis enquanto o produto químico é aplicado e declinar quando cessa a aplicação, dependendo da adaptabilidade das formas resistentes para sobreviver sob condições de ausência da pressão de seleção. Miura e Takahashi (1976) citados por UESUGI (1978), observaram que embora nenhum fator imprōprio para sobrevivência fosse encontrado nos mutantes kasugamicina-resistentes de Pyricutaria oryzae, sua população decresceu apös cessar a aplicação do antibiōtico e praticamente desapareceu depois de 4 anos. Um comportamento similar ocorreu com linhagens de Puccinia horiana resistentes a oxycarboxin, segundo Abiko e kishi (não publicado)citados por UESUGI (1978). Por outro lado, linhagens de Botrytis resistentes a benomyl e tiofanato-metil algumas vezes sobreviveram, mesmo depois que a aplicação desses fungicidas foi suspersa (UESUGT, 1978).

Em experimentos de laboratōrio foram obtidas linhagens de Ciadosporium cucumerinum e Eusamizm oxysporm f. sp. narcissi resistentes a pimaricin, que mostraram redução na esporulação in vitro e na patogenicidade (DEKKER, 1982a).

A adaptabilidade de linhagens resistentes aos benzimidazöis parece variar extensamente. Algumas vezes tem sido relatada ser igual àquela dos patógenos sensỉveis, como foi mostrado para resistência a benomyl e thiabendazol em Penieillizm digitatum, cujo mutante resisten te não apresentou redução na patogenicidade (WILD e RIPPON, 1975). Tambëm os experimentos de RUPPEL (1975) levarama interpretações semelhantes, 
desde que as formas benomyl-resistentes de Cercospora beticola não diferiram das sensỉveis em crescimento e esporulação in vitro nem em virulência e esporulação in vivo. Além disso, DovAs et aliz (1976) constataram que a frequência de linhagens resistentes na população natural de C. beticola na Grécia, não declinou, mesmo 3 anos apös a interrupção no uso de benomyl. E mesmo 10 anos depois que os benzimidazóis foram re tirados na Holanda, resistência de Sphaerotheca fuliginea (oỉdio do pepino) a eles, tem sido persistente (SCHEPERS, 1984).

Mas há casos em que a habilidade competitiva dos indivíduos resistentes aos benzimidazóis se torna prejudicada. Assim, verificou-se que dois isolados de Monitinia laxa de damasco, resistentes a benomyl, se tornaram menos patogênicos e produziram menor quantidade de coñ̈dios em meio de cultura sem fungicida (OGAWA et alii, 1984).

Enquanto as evidências têm comprovado que resistência aos benzimidazóis é estāvel e particularmente em relação a benomyl, em quase todos os casos, não parece estar absolutamente ligada à redução de adaptabilidade (DEKKER, 1982a; BEEVER e BRIEN, 1983), a estabilidade da resistência aos dicarboximidas é aparentemente muito baixa (LORENZ e POMMER, 1982) e os mutantes dicarboximida-resistentes apresentam um decréscimo na habilidade competitiva (BEEVER e BYRDE, 1982; BEEVER e BRIEN, 1983)。

Em experimentos conduzidos por PANAGIOTAKU e MALATHRARIS (1981), observou-se que o crescimento das linhagens de Botrytis cinerea resistentes a dicarboximidas em meio de BDA, foi mais lento do que o das linhagens sensiveis, mas os esporos germinaram igualmente bem em ambos 
os casos; além disso, plantas tratadas com vinclozolin foram facilmente infectadas quando inoculadas com uma suspensão de esporos resistentes.

Para se avaliar a habilidade competitiva in vitro e in vivo de linhagens de $B$. cinerea sensíveis e resistentes a dicarboximidas, foi utilizada uma mistura de conidios sensiveis e resistentes para inocular placas com meio de cultura isento de fungicida. A proporção de esporos resistentes e sensíveis foi então determinada durante 4 ciclos de gerações; constatou-se que, de uma forma geral, houve o desaparecimento dos mutantes resistentes, e em apenas um caso a linhagem resistente foi tão competitiva quanto a sensível. Essa mesma linhagem, quando inoculada em plantas tratadas e não tratadas com vinclozolin, foi reisolada apōs 2-3 meses, mas somente a uma frequência muito baixa (GULLINO e GARIBALDI, 1981).

HISADA et ali (1981) tambēm empregaram uma mistura de esporos de $B$. cinerea sensiveis e resistentes a procymidone para inocular plantas, e constataram que as linhagens resistentes desapareceram depois de um certo tempo, na ausência da pressão de seleção. Todavia, com aplicações de procymidone a população resistente aumentou gradualmente, voltando a diminuir quando o fungicida foi novamente retirado. E mesmo nos casos em que a população resistente foi alta, o tratamento com procymidone foi ainda eficiente no controle da doença.

Quando uma mutação torna o mutante mais resistente do que o tipo selvagem a um produto químico e mais sensível do que o tipo se1vagem a outro produto químico, tal fenômeno è conhecido como resistência 
cruzada correlacionada negativamente, ou seja, sensibilidade colateral (GEORGOPOULOS, 1982). Assim, observou-se que mutantes de Pyricularia oryzae resistentes a fosforotiolates (Kitazin P), mostraram um aumento de sensibilidade a fosforamidates, e vice-versa (UESUGI et alii, 1974). A ocorrência de sensibilidade colateral também foi verificada por LAMBERT e WUEST (1975), ao constatarem que conidios de 4 isolados de Verticizlium malthousei resistentes a benomyl foram mais sensíveis a zineb do que conidios de 4 isolados sensíveis a benomyl. Alëm disso, constatou-se que um isolado benomyl-resistente de Monilinia fructicola cresceu tão räpido quanto um isolado sensível sobre um meío sem fungicida, mas cresceu mais lentamente do que o tipo selvagem sobre um meio contendo captan ou prochloraz (DIJKHUIZEN et alii, 1983). 
3. MATERIAL E METODOS

3.1. Isolamento.

Foram obtidos 52 isolados do fungo Botrytis cinerea a partir de frutos de morango apresentando sintomas típicos de mofo cinzento, provenientes de 5 localidades do estado de São Paulo (Tabela 1).

\subsection{Técnica de Isolamento}

Para se proceder ao isolamento do fungo foram utilizadas placas de Petri contendo meio de cultura de BDA (extrato de $200 \mathrm{~g}$ de batata;dextrose - 20g; ägar - 18g; ägua destilada - q.s.p. - $1000 \mathrm{ml}$ ), procurando-se transferir para as placas apenas os esporos do fungo e quando isto não foi possível, o pröprio micélio foi utilizado como inóculo, uti.lizando-se um estilete. As placas foram mantidas sob condições de câmara ambiente (Biotronette Mark III, Lab-Line Instruments), com temperatura ao redor de $21^{\circ} \mathrm{C}$ e luminosidade constante. A luminosidade foi fornecida por duas lâmpadas fluorescentes, luz dodia, de 40 watts, 


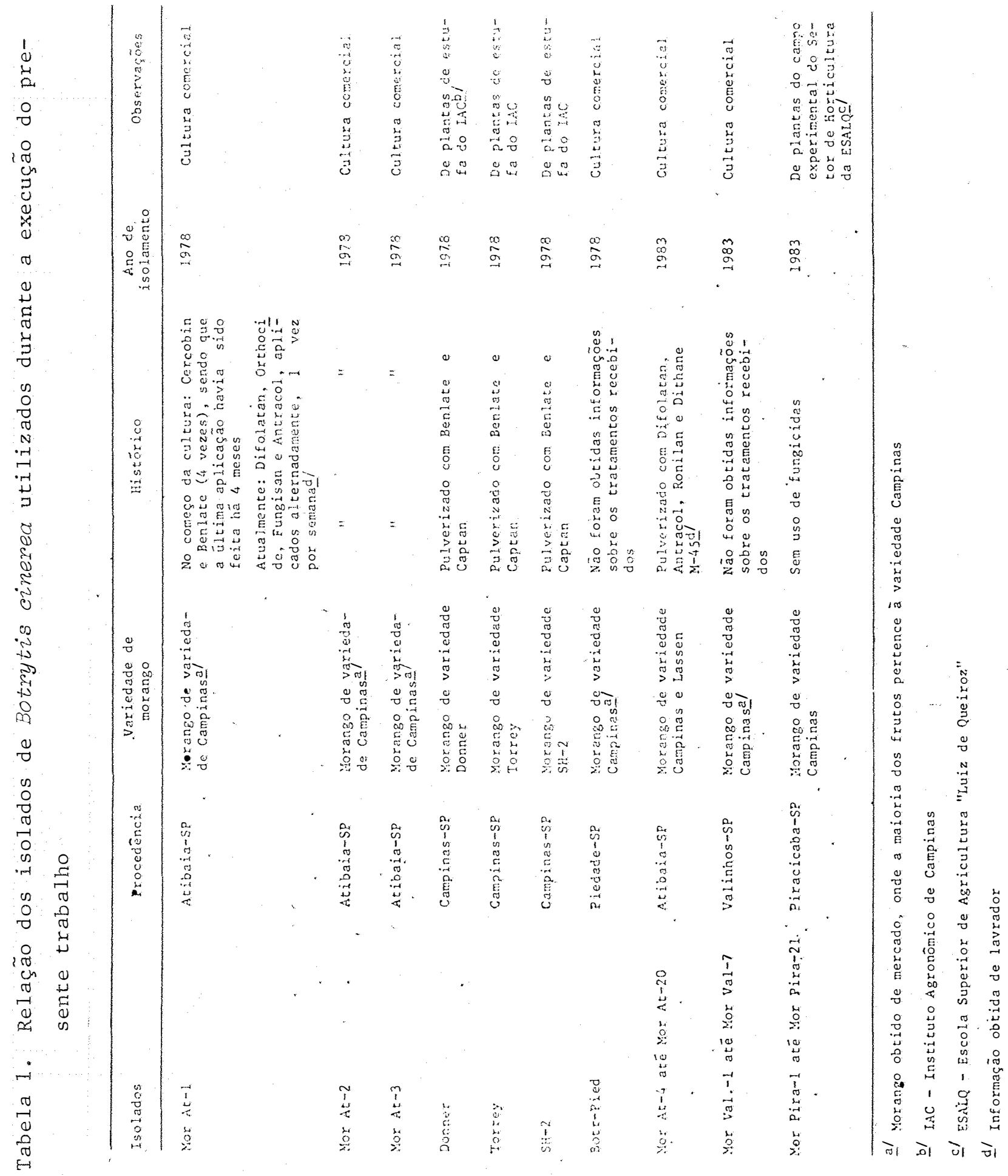


colocadas aproximadamente a $34 \mathrm{~cm}$ acima das placas. Três a quatro dias após o isolamento, o fungo já tomava praticamente dois terços das placas, tendo as colônias atingido um diâmetro ideal para se dar início aos experimentos.

\subsection{Preservação do Fungo.}

A preservação dos 52 isolados de Botrytis cinerea inicialmente foi feita através de repicagens sucessivas utilizando-se o meio de BDA, e posteriormente empregou-se o método de Castellani, descrito por FIGUEIREDO (1967). De acordo com este método, discos de micélio do fungo foram transferidos para vidros de penicilina, com capacidade de $6 \mathrm{ml}$, contendo 4 a $5 \mathrm{ml}$ de ägua destilada esterilizada; a seguir, os vidros foram tamponados com rolhas de borracha, lacrados com tampas hermëticas de alumínio (usando-se para isso, mäquina cravadora especial) e mantidos sob temperatura ao redor de $10^{\circ} \mathrm{C}$.

A eficiência do método de Castellani na conservação da viabilidade das culturas de fungos e bactérias mantidas em água destilada por longos períodos de tempo, sem necessidade de repicagens, tem sido ressaltada em vários trabalhos (FIGUEIREDO, 1967; 1971; PEREIRA et alii, 1970; FIGUEIREDO e PIMENTEL, 1975; BOESEWINKEL, 1976 e HECKLY, 1978). Além da preservação da viabilidade, esporulação e características morfológicas, há relatos de que também as características patogênicas dos microorganismos podem ser mantidas em muitos casos. Este fato foi revelado através dos trabalhos conduzidos por PIMENTEL et alii (1980), 
onde foi observado que de 9 culturas de fungos inoculadas em seus respectivos hospedeiros, após terem sido submetidas ao processo de conservaçao em àgua destilada por mais de 7 anos, 6 mantiveram sua patogenici dade inalterada.

3.4. Preparo dos Meios de Cultura com Fungicidas.

Para o preparo dos meios de cultura com os fungicidas seguiu-se a técnica de EDGINGTON et alii (1971), modificada por MENTEN et alii (1976), dissolvendo-se os produtos inicialmente em acetona $(5,0 \mathrm{ml})$ e completando-se o volume para 100ml com água destilada esterilizada. Desta solução estoque foram feitas diluições em série e tomada uma alíquota de 1,0ml de cada suspensão e transferida para 100ml de meio de cultura BDA fundente $\left(45\right.$ a $47^{\circ} \mathrm{C}$ ), de tal forma a se obter as concentrações desejadas.

\subsection{Experimentos Realizados}

3.5.1. Frequência de isolados de Botrytis cinerea resistentes ao fungicida benomyl, em condições de campo

Os 52 isolados de Botrytis cinerea foram testados em relação à ocorrência de possĩveis mutantes resistentes, em condições de laboratório.

Este ensaio foi realizado em duas épocas diferentes, ou seja, em 1978 foram testados os isolados Mor At-1, Mor At-2, Mor At-3, Donner, Torrey, SH-2 e Botr-Pied, e posteriormente, em 1983, foram 
testados os isolados restantes, de acordo com a Tabela 1 .

Os isolados foram primeiramente cultivados em meio de BDA e após 6 dias de incubação, uma pequena porção de inóculo de cada isolado foi transferida para placas contendo meio de BDA suplementado com 100ppm de benomy l, usando-se um estilete. Para cada placa foram repicados 4 isolados diferentes, tendo sido a mesma previamente dividida, no verso, em 4 compartimentos (usando-se canetahidrocor) e colocando-se cada isolado no local correspondente à sua referência.

Cada ensaio contou com 2 repetições e a incubação das placas se deu sob luz contínua, fornecida por 2 lâmpadas fluorescentes, luz do dia, de 40 watts, clocadas a uma altura entre 24 e $34 \mathrm{~cm}$ e temperatura ao redor de $21^{\circ} \mathrm{C}$, em condições de câmara ambiente (Biotronette Mark III, Lab-Line Instruments).

As placas faram observadas diariamente at $\vec{e} 6$ dias após a repıcagem, procurando-se notar se havia crescimento dos isolados ou nao.

3.5.2. Resposta in vitro de isolados de Botrytis cinerea sensíveis e resistentes ao benomyl, a doses crescentes do fungicida

0 presente experimento foi instalado com o intuito de se obter informações mais detalhadas sobre o comportamento de isolados sensiveis e resistentes ao benomyl, frente a concentrações de 1,10 e 100ppm do fungicida. 
Na execuçäo deste ensaio, realizado em 1978, foram utilizados 4 isolados sensiveis (Donner, Torrey, SH-2 e Botr-Pied.) e 3 resistentes (Mor At-1, Mor At-2 e Mor At-3).

Após 4 dias de crescimento em meio de BDA, quando os 7 isolados já haviam atingido aproximadamente dois terços das placas, foram retirados inóculos do fungo, utilizando-se para isso um furador de rolhas para que tivessem o mesmo diâmetro $(1,0 \mathrm{~cm})$. Tais inóculos foram retirados dos bordos das colônias, pois as pontas hifälicas apresentam taxa de crescimento superior a do micélio mais velho e, em seguida colocados no centro de placas contendo meio de BDA suplementado com 3 crescentes concentrações de benomyl, a saber: 1, 10 e 100ppm, havendo, naturalmente, para cada isolado a placa-controle contendo apenas BDA (testemunha). Foram feitas 3 repetições para cada concentração do fungicida, incluindo-se tambëm as testemunhas, num total de 84 placas. Tais placas for am mantidas sob as mesmas condições citadas no experimento descrito no item 3.5.1., sendo que o delineamento experimental foi inteiramente casualizado.

O desenvolvimento dos isolados do fungo foi acompanha-

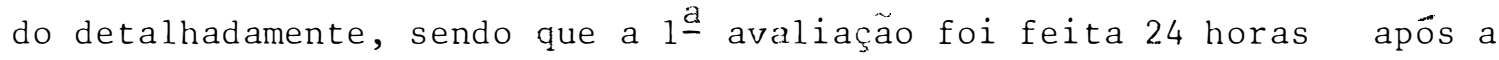
instalação do experimento, colocando-se cada placa em um contador de colônias (Darkfield Quebec Colony Counter), marca Spencer, e medindo-se o crescimento diametral da colônia com régua, pelo verso das placas de Petri; esta operação foi repetida a cada 24 horas até o 50 dia, quando o fungo atingiu os bordos das placas-testemunha. 
3.5.3. Nível de resistência dos mutantes ao benomyl

Este ensaio foi conduzido em 1983 com o objetivo de se descobrir o grau de resistência de alguns dos 12 isolados de $B$. cinerea resistentes ao benomyl, alëm de novamente se estabelecer comparações en tre o crescimento de isolados sensíveis e resistentes, na ausência do fungicida e em doses crescentes do mesmo. Neste sentido, foram testados os isolados resistentes: Mor At-5, Mor At-7, Mor At-9 e Mor At-10 e o sensível Mor At-20.

Os 5 isolados de $B$. cinerea foram inicialmente cultivados em meio de BDA e com 4 dias de idade foram retirados da periferia das colônias, discos do micélio do fungo, com o auxílio de um furador de rolhas de $0,7 \mathrm{~cm}$ de diâmetro. A seguir procedeu-se à inoculação, no centro de placas contendo meio de BDA acrescido de 4 dosagens de benomyl (1, 10, 100 e $1000 \mathrm{ppm})$, além das placas-testemunha. Este experimento contou com 3 repetiçöes para cada isolado nas placas-controle e nas 4 crescentes concentrações do fungicida, num total de 75 placas.

As placas assim inoculadas foram incubadas sob as mesmas condições jä citadas em ensaios anteriores e o delineamento experimental foi inteiramente casualizado. A $1 \stackrel{\text { a }}{\text { le }}$ letura foi feita 48 horas após a inoculação, colocando-se cada placa no contador de colônias já referido no experimento anterior,e tomando-se 2 medidas do crescimento diametral da colônia em direções perpendiculares entre si, pelo verso de cada placa. Este procedimento foi repetido posteriormente com intervalos de 24 horas até o 69 dia, totalizando 5 avaliações, quando o 
crescimento das testemunhas atingiu os bordos das placas.

$$
\begin{aligned}
& \text { 3.5.4. Avaliação da esporulação de um isolado de Botrytis } \\
& \text { cinerea sensível e de quatro resistentes, em meio de } \\
& \text { cultura isento de benomyl }
\end{aligned}
$$

Com a finalidade de se comparar a capacidade de esporulação de isolados sensíveis e resistentes a benomÿl, na ausência deste, foram testados no ano seguinte, os mesmos isolados de B. cinerea empregados no experimento anterior, ou seja, os resistentes Mor At-5, Mor At-7, Mor At-9 e Mor At-10 e o sensível Mor At-20.

Foram utilizadas 5 repetiçōes de cada isolado mencionado acima em meio de BDA, com 8 dias de idade.

As suspensões de esporos foram preparadas colocando-se $20 \mathrm{ml}$ de ägua destilada esterilizada em placas de Petri contendo as cul turas füngicas, e estas friccionadas, levemente, com o auxỉlio de uma alça de "Drigalski", sendo a suspensão filtrada através de uma camada de gaze e outra de algodão, para eliminar os resíduos.

A avaliação da esporulação foi feita por colorimetria (Co lorímetro BAUSCH LOMB \& SPECTRONIC 20, a $625 \mathrm{~nm})$. Previamente calibrouse uma suspensão (em hemocitômetro) e suas diluições foram correlacionadas com a densidade öptica, segundo a equação:

$$
y=0,12074+8,78850 x
$$

onde: $y=n$ e de esporos $\left(x 10^{6}\right) / \mathrm{ml}$

$$
\mathrm{x}=\text { densidade óptica a } 625 \mathrm{~nm}
$$


3.5.5. Sensibilidade colateral in vitro de quatro isolados de Botrytis cineroea resistentes e um sensível ao benomyl, a quatro fungicidas

Os 4 isolados resistentes ao benomyl (Mor At-5, Mor At-7, Mor At-9 e Mor At-10) e o sensível (Mor At-20), jā empregados em ensaios anteriores, foram comparados quanto a sua sensibilidade colateral in vitro frente a 4 fungicidas (Tabela 2) nas concentrações de 0,1 , 10, 100 e 1000ppm. Tais fungicidas foram testados devido ao seu uso na cultura comercial do morango.

A metodologia de inoculação, incubação e avaliação das placas foram as mesmas empregadas no ensaio descrito no item 3.5.3.

o delineamento estatístico foi inteiramente casualizado, com 5 tratamentos (isolados) e 3 repetições, num total de 75 placas em cada ensaio.

3.5.6. Competição in vitro entre um isolado de Botrytis einerea sensivel e outro resistente ao benomyl

Este experimento, realizado em 1979, teve por objetivo se avaliar em condições de laboratório, a capacidade competitiva entre um isolado resistente e um sensivel de $B$. cinerect, na ausência de benomy 1 . 


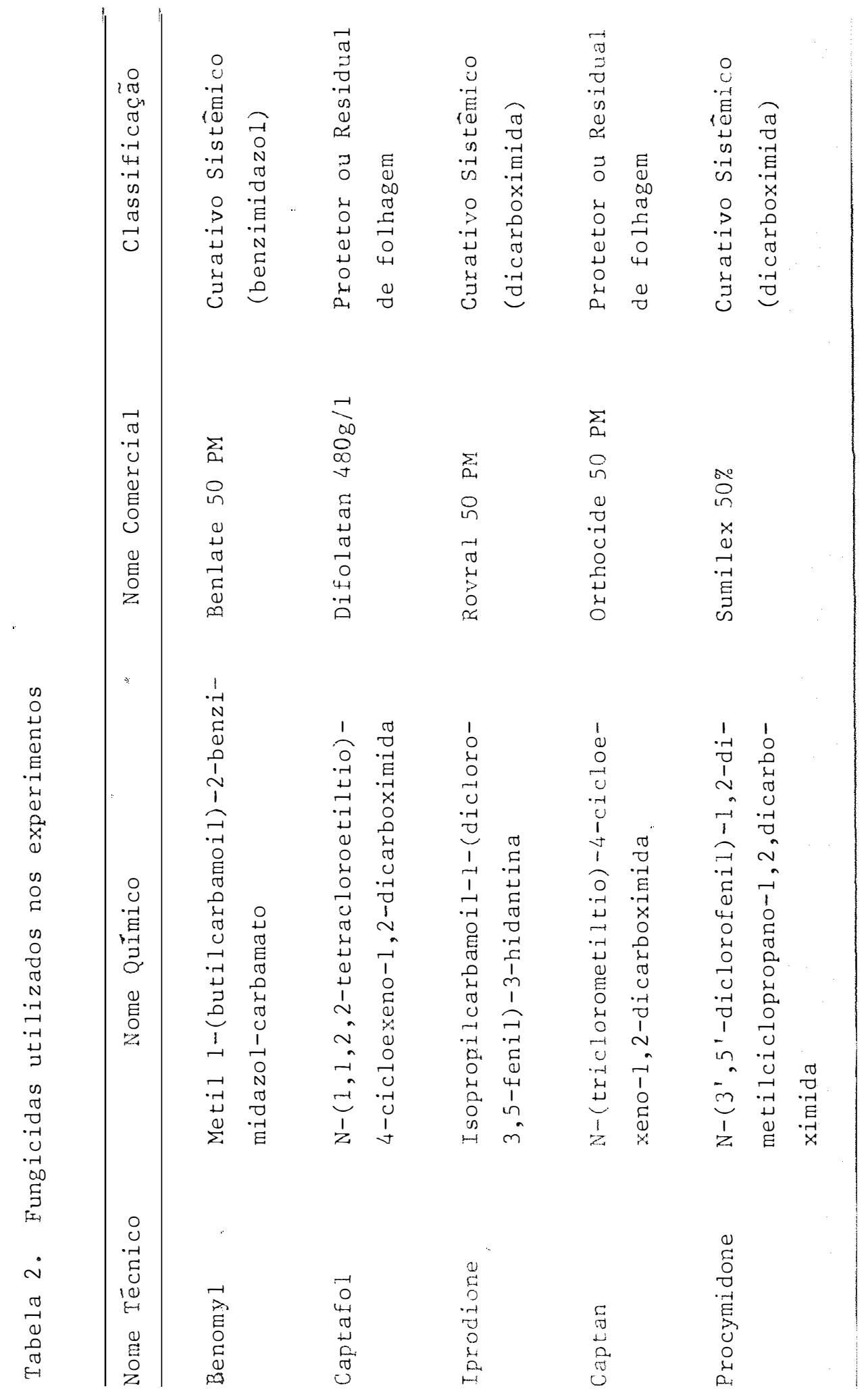


3.5.6.1. Obtenção de uma suspensão constituída pela mistura de esporos de um isolado de $B$. cinerea sensivel e de outro resistente ao benomyl

Para se proceder à mistura de esporos de ambos os isolados, foram escolhidos, dentre os 7 isolados obtidos em 1978, 2 que apre sentavam características bem marcantes em relação à sensibilidade e resistência ao fungicida benomy 1, ou seja, os isolados SH-2 e Mor At-1, respectivamente, conforme mostram os dados da Tabela 5 (Capítulo 4, Resultados).

A procedência dos dois isolados utilizados estā descrita na Tabela 3.

A suspensão de esporos de cada isolado de $B$. cinerea foi obtida colocando-se, com auxilio de alça de platina, esporos dos isolados Mor At-1 e SH-2, independentemente, em 2 tubos de ensaio contendo 99,9m1 de āgua destilada esterilizada mais $0,1 \mathrm{~m} 1$ de solução de Tween 80. A seguir foi feita a leitura em hemocitômetro, sendo que a concentração de esporos do isolado resistente ao benomyl foi quase o dobro do sensível, ou seja, $53 \times 10^{4}$ esporos/ml para o isolado resistente e $28 \times 10^{4}$ esporos/m1 para o sensivel.

Posteriormente foi feita a mistura dos esporos de ambos os isolados, colocando-se $2 \mathrm{~m} 1$ de cada suspensão em um tubo de ensaio (volume final de $4 \mathrm{~m} 1$ ). 


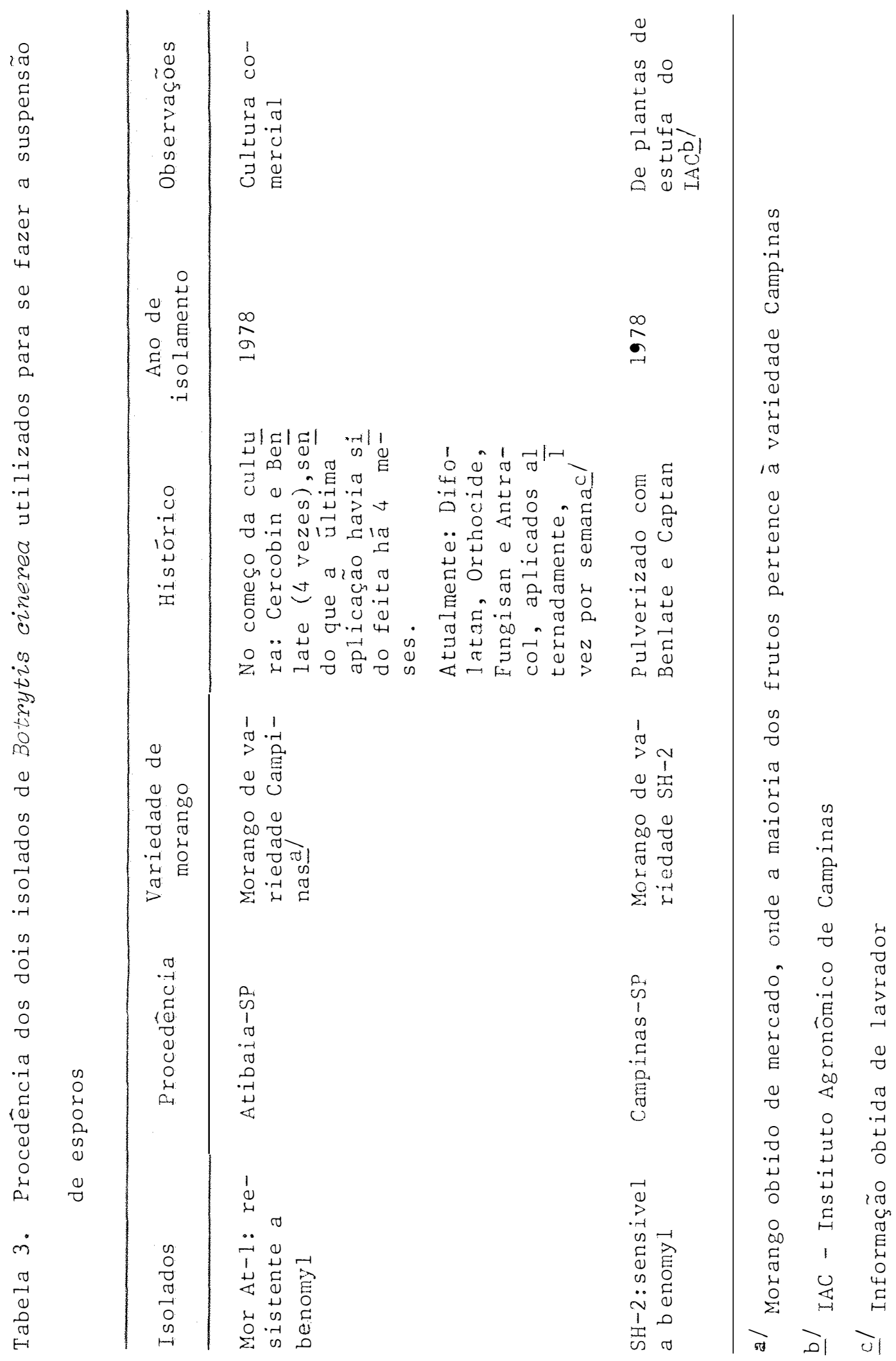


3.5.6.2. Diluiçöes da suspensão obtida e plaqueamento dos esporos

A partir da suspensão constituída pela mjistura de esporos dos dois isolados, sensível e resistente, foi feita uma série de diluições, das quaís foram plaqueadas apenas as $3 \bar{u} 1$ timas, ou seja, aquelas com concentrações de esporos estimadas em 4,05 x 10 $3,4,05 \times 10^{2}$ e $4,05 \times 10^{1}$ conídios/m1.

Os esporos foram semeados em placas contendo 2 tipos de meios de cultura, a saber, BDA e BDA suplementado com 100ppm de benomyl. O plaqueamento dos conídios se deu colocando-se, com o auxílio de uma pipeta, 0,lml da suspensäo em cada placa e espalhando-se com alça de "Drigalski". Para a diluição mais concentrada, ou seja, a que continha aproximadamente $4,05 \times 10^{3}$ conídios/m1, foram feitas 5 repetições em meio de BDA e 5 em meio de BDA mais $100 \mathrm{ppm}$ de benomyl, enquanto que para as outras duas restantes, foram feitas 10 repetições em cada tipo de meio.

As 50 placas foram mantidas sob condições idênticas às jä citadas em experimentos anteriores.

Foram feitas avaliaçöes apös 48, 72 e 96 horas da instalação do ensaio, quando jả não havia mais possibilidade de aparecerem novas colônias, contando-se o nümero de esporos peloversodas placas de Petri. 
A segunda fase do experimento foi montada 7 dias após a instalação da primeira. Da mesma forma, foram montadas outras fases sucessivamente atē a quinta, com intervalo de aproximadamente 7 dias en tre cada uma delas. Todo o procedimento empregado para estas demais fases que se sucederam, foi idêntico ao da primeira, ou seja, foram utilizadas diluições de esporos dos isolados resistente e sensível con tidos em placas com BDA, sendo as contagens de viāveis feitas após 48, 72 e 96 horas da instalaçäo de cada ensaio. 
4. RESULTADOS

\subsection{Frequência de Isolados de Botrytis cinerea Resistentes ao Fun- gicida Benomy1, em Condições de Campo.}

Dentre os 52 isolados de Botrytis cinerea obtidos de fru tos de morango procedentes de Atibaia, Campinas, Piedade, Valinhos e Piracicaba, pode-se notar, de acordo com a Tabela 1, que 23 foram provenientes de frutos de morango tratados com benomyl e/ou outro(s) fungicida(s), 21 foram obtidos de frutos que não receberam qualquer tratamento e de 8 não foi possível se obter informaçöes sobre a aplicação ou não de algum produto químico. Observando-se a Tabela 4, verifica-se que dos 23 isolados acima citados, foram encontrados 12 resistentes a 100ppm de benomyl (sendo todos obtidos de morangos procedentes de Atibaia), e que nenhum caso de resistência foi constatado entre os 21 isolados provenientes de frutos não tratados procedentes de Piracicaba, o mesmo acontecendo com os 8 isolados restantes. 
Tabela 4. Frequência de isolados de Botrytis cinerea de morango resistentes a 100 ppm de benonyl

\begin{tabular}{|c|c|c|c|c|}
\hline \multirow{2}{*}{ Procedência } & \multirow{2}{*}{$\begin{array}{c}\text { Ano de } \\
\text { isolamento }\end{array}$} & \multicolumn{3}{|c|}{ ne de isolados } \\
\hline & & Testados & Sensiveis & Resistentes \\
\hline Atibaia-SP (cc) a / & 1978 & 3 & 0 & 3 \\
\hline Campinas-SP (IAC) b/ & 1978 & 3 & 3 & 0 \\
\hline Piedade-SP (cc) a / & 1978 & 1 & 1 & 0 \\
\hline Atibaia-SP (cc) al & 1983 & 17 & 8 & 9 \\
\hline Valinhos-SP (cc) a/ & 1983 & 7 & 7 & 0 \\
\hline 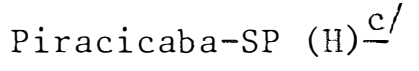 & 1983 & 21 & 21 & 0 \\
\hline Total & & 52 & 40 & 12 \\
\hline
\end{tabular}

a/ cc - Cultura comercial

b/ IAC - Instituto Agronômico de Campinas

c/ H - De plantas do campo experimental do Setor de Horticultura da ESALQ

Obs.: O critêrio empregado para se designar os isolados como sensiveis ou resistentes a benomyl, foi o crescimento ou não em meio de BDA mais 100 ppm do fungicida. Os que não cresceram foram considerados sensiveis e os que cresceram foram considerados resistentes. 
4.2. Resposta in vitro. de Isolados de Botrytis cinerea Sensiveis e $\underline{\text { Resistentes ao Benomyl, a Doses Crescentes do Fungicida }}$

Os resultados obtidos com a realização deste ensaio, revelaram que não houve diferença significativa no comportamento de isolados de $B$. cinerea sensíveis e resistentes, quando em meio de BDA; mas em presença de doses crescentes de benomyl, a vantagem dos isolados resistentes foi nitidamente evidenciada (Tabela 5).

Embora em meio de cultura isento de fungicida, isolados resistentes e sensíveis não tenham diferido estatisticamente, foi possí vel se observar, dentro destas limitaçöes, um crescimento diametral um pouco mais acentuado dos isolados sensíveis em relação aos resistentes. Neste sentido, verificou-se que os isolados cujas colônias apresentaram maior desenvolvimento em meio de BEA após 3 dias de incubação, foram os sensiveis SH-2, seguido por Torrey e Botr-Pied., sendo que este ü1timo teve crescimento idêntico ao do isolado resistente Mor At-3.

Foi constatada uma certa uniformidade no comportamento dos isolados resistentes, nas 3 crescentes concentrações do fungicida. Assim, observou-se que o isoladoque apresentou maior crescimento micelial foi, nas 3 situações, Mor At-1, seguido por Mor At-2 e Mor At-3, o que resultou na mesma sequência em relação às médias de crescimento diametral das colônias.

Verificou-se tambëm que, apesar dos isolados resistentes terem tido capacidade para crescerem a 1 , 10 e 100ppm do fungicida, esta ültima concentração teve influência mais acentuadas sobre eles. 
Tabela 5. Crescimento micelial de sete isolados de Botrytis cinerea aos três dias de incubação, em meio de BDA contendo diferentes concentrações de benomy 1

\begin{tabular}{|c|c|c|c|c|c|}
\hline \multirow[t]{2}{*}{ Isolados } & \multicolumn{4}{|c|}{$\begin{array}{c}\text { Crescimento diametral das colônias (em cm) a } \\
\text { nas concentraçôes de benomyl indicadas } \\
(\text { em ppm) }\end{array}$} & \multirow[t]{2}{*}{ Média } \\
\hline & 0 & 1,0 & 10,0 & 100,0 & \\
\hline Mor At-1 (R) & $\begin{array}{c}6,20 a \\
A\end{array}$ & $\begin{array}{c}6,00 a \\
A\end{array}$ & $\begin{array}{c}6,20 \mathrm{a} \\
\mathrm{A}\end{array}$ & $\begin{array}{c}3,80 a \\
B\end{array}$ & $5,55 a$ \\
\hline Mor At-2 (R) & $\begin{array}{c}5,80 a \\
A\end{array}$ & $\begin{array}{c}5,10 a \\
A\end{array}$ & $\begin{array}{c}5,16 a \\
A\end{array}$ & $\begin{array}{c}2,53 a \\
B\end{array}$ & $4,64 b$ \\
\hline Mor At-3 (R) & $\begin{array}{c}6,56 a \\
A\end{array}$ & $\begin{array}{c}4,76 a \\
B\end{array}$ & $\begin{array}{c}4,93 \mathrm{a} \\
\mathrm{B} .\end{array}$ & $\begin{array}{c}2,23 a \\
C\end{array}$ & $4,62 b$ \\
\hline Donner (S) & $\begin{array}{c}5,40 a \\
A\end{array}$ & $\begin{array}{c}0,40 \mathrm{~b} \\
\mathrm{~B}\end{array}$ & $\begin{array}{c}0,13 b \\
B\end{array}$ & $\begin{array}{l}\mathrm{Ob} \\
\mathrm{B}\end{array}$ & $1,48 \mathrm{c}$ \\
\hline Torrey (S) & $\begin{array}{c}6,63 a \\
A\end{array}$ & $\begin{array}{c}0,36 b \\
B\end{array}$ & $\begin{array}{c}0,36 \mathrm{~b} \\
\mathrm{~B}\end{array}$ & $\begin{array}{c}0,33 b \\
B\end{array}$ & $1,92 \mathrm{c}$ \\
\hline $\mathrm{SH}-2 \quad(\mathrm{~S})$ & $\begin{array}{c}6,83 a \\
A\end{array}$ & $\begin{array}{c}0,73 b \\
B\end{array}$ & $\begin{array}{c}0,26 \mathrm{~b} \\
\mathrm{~B}\end{array}$ & $\begin{array}{l}\mathrm{Ob} \\
\mathrm{B}\end{array}$ & $1,95 \mathrm{c}$ \\
\hline Botr-Pied (S) & $\begin{array}{c}6,56 a \\
A\end{array}$ & $\begin{array}{c}0,50 \mathrm{~b} \\
\mathrm{~B}\end{array}$ & $\begin{array}{c}0,16 \mathrm{~b} \\
\mathrm{~B}\end{array}$ & $\begin{array}{c}0,43 \mathrm{~b} \\
\mathrm{~B}\end{array}$ & $1,91 \mathrm{c}$ \\
\hline Média & $\begin{array}{c}6,28 \\
A\end{array}$ & $\begin{array}{c}2,55 \\
B\end{array}$ & $\begin{array}{c}2,45 \\
B\end{array}$ & $\begin{array}{c}1,33 \\
C\end{array}$ & \\
\hline
\end{tabular}

a/ Média de três repetições, sendo que cada placa foi inoculada com um disco de micélio de $1,0 \mathrm{~cm}$ de diâmetro. Avaliação no terceiro dia após a inoculação. Médias seguidas pela mesma letra, minúsculas nas colunas e maiúsculas nas linhas, não diferen entre si pelo teste de Tukey a $5 \%$.

(R): isolado resistente a benomyl

(S): isolado sensível a benomyl 
Outro fato a ser ressaltado ē que năo obstante 2 isolados sensiveis (Torrey e Botr-Pied.) terem apresentado um pequeno crescimento em presença de 100 pm de benomyl, isto não quer dizer que ambos difiram efetivamente dos outros dois sensíveis, já que estatisticamente eles comprovaram serem iguais.

4.3. Nivel de Resistência dos Mutantes ao Benomyl.

De acordo com os dados da Tabela 6, constatou-se que na ausência de benomyl, os isolados resistentes tiveram um desenvolvimento um pouco mais reduzido do que o do isolado sensivel. Mas a comparação do crescimento diametral dos 5 isolados nas 4 crescentes dosagens do fungicida, evidenciou claramente a aptidäo dos isolados resistentes de se desenvolverem em tais condiçōes adversas, ao conträrio do sensível, o qual teve seu crescimento drasticamente reduzido, jä a $1 \mathrm{ppm}$ de benomy 1 .

Desta forma, verificou-se que os 4 isolados resistentes manifestaram ter capacidade de crescimento em situações de atë 1000ppm de benomyl. Excluindo-se Mor At-9, os demais isolados resistentes tiveram uma redução gradativa no seu crescimento micelial, à medida que as concentraçōes do fungicida foram se tornando mais elevadas; isto so não foi observado em relação à dosagem mais alta, de 1000ppm, onde a diminuição no diâmetro das colônias de tais isolados foi bastante signi ficativa, quando comparado com o ocorrido na concentração anterior.

Dentre os isolados resistentes, o Mor At-5 foi o que apresentou o mais intenso crescimento, tanto em BDA como em BDA acrescido 
Tabela 6. Crescimento micelial de cinco isolados de Botrytis cinerea aos quatro dias de incubação, em meio de cultura de BDA contendo diferentes concentrações de benomy 1

\begin{tabular}{|c|c|c|c|c|c|c|}
\hline \multirow[t]{2}{*}{ Isolados } & \multicolumn{5}{|c|}{$\begin{array}{c}\text { Crescimento diametral das colônias (em cm) al } \\
\text { nas concentraçôes de benomyl indicadas } \\
(\text { em ppm) }\end{array}$} & \multirow[t]{2}{*}{ Média } \\
\hline & 0 & 1,0 & 10,0 & 100,0 & 1000,0 & \\
\hline Mor At-5 (R) & $\begin{array}{c}7,55 \mathrm{a} \\
\mathrm{AB}\end{array}$ & $\begin{array}{c}7,76 \mathrm{a} \\
\mathrm{A}\end{array}$ & $\begin{array}{c}7,40 \mathrm{a} \\
\mathrm{AB}\end{array}$ & $\begin{array}{c}6,65 \mathrm{a} \\
\mathrm{B}\end{array}$ & $\begin{array}{c}1,08 \mathrm{a} \\
\mathrm{C}\end{array}$ & $6,08 \mathrm{a}$ \\
\hline Mor At $-7 \quad(R)$ & $\begin{array}{c}6,23 b c \\
A\end{array}$ & $\begin{array}{c}6,65 b \\
A\end{array}$ & $\begin{array}{c}6,56 a b \\
A\end{array}$ & $\begin{array}{c}6,18 \mathrm{ab} \\
\mathrm{A}\end{array}$ & $\begin{array}{c}0,78 a b \\
B\end{array}$ & $5,28 b$ \\
\hline Mor At-9 (R) & $\begin{array}{c}6,71 \mathrm{ab} \\
\mathrm{A}\end{array}$ & $\begin{array}{c}6,25 b \\
A\end{array}$ & $\begin{array}{c}4,35 c \\
B\end{array}$ & $\begin{array}{c}1,71 \mathrm{c} \\
\mathrm{C}\end{array}$ & $\begin{array}{c}0,88 \mathrm{ab} \\
\mathrm{C}\end{array}$ & $3,98 d$ \\
\hline Mor At-10 (R) & $\begin{array}{c}5,50 c \\
A\end{array}$ & $\begin{array}{c}5,8.3 \mathrm{~b} \\
\mathrm{~A}\end{array}$ & $\begin{array}{c}5,71 b \\
A\end{array}$ & $\begin{array}{c}5,1.5 b \\
A\end{array}$ & $\begin{array}{c}0,91 \mathrm{ab} \\
\mathrm{B}\end{array}$ & $4,62 c$ \\
\hline Mor At-20 (S) & $\begin{array}{c}7,68 \mathrm{a} \\
\mathrm{A}\end{array}$ & $\begin{array}{c}1,06 c \\
B\end{array}$ & $\begin{array}{c}0,45 \mathrm{~d} \\
B C\end{array}$ & $\begin{array}{l}\mathrm{Od} \\
\mathrm{C}\end{array}$ & $\begin{array}{l}\mathrm{Ob} \\
\mathrm{C}\end{array}$ & $1,83 \mathrm{e}$ \\
\hline Média & $\begin{array}{c}6,73 \\
A\end{array}$ & $\begin{array}{c}5,51 \\
B\end{array}$ & $\begin{array}{c}4,89 \\
C\end{array}$ & $\begin{array}{c}3,93 \\
D\end{array}$ & $\begin{array}{c}0,73 \\
E\end{array}$ & \\
\hline
\end{tabular}

a/ Média de três repetiçũes, sendo que cada placa foi inoculada com um disco de micélio de $0,7 \mathrm{~cm}$ de diâmetro. Avaliação no quarto dia após a inoculação. Médias seguidas pela mesma letra, minúsculas nas colunas e maiüsculas nas linhas, não diferem entre si pelo teste de Tukey a $5 \%$.

$(R)$ : isolado resistente a benomy 1

(S): isolado sensỉvel a benomyl 
de diferentes concentrações do fungicida benomyl, alëm de ter sido o isolado que dos 5, alcançou a maior média de crescimento diametral.

\subsection{Avaliação da Esporulação de Um Isolado de Botrytis cinerea Sensível e de Quatro Resistentes, em Meio de Cultura Isento de. Benomy}

Os resultados deste experimento, feito com o intuito de se avaliar a esporulação dos 5 isollados de $B$. einerea revelaram, como jä se supunha anteriormente, que em meio de BDA, ou seja, na ausência de fungicida, o isolado sensível (Mor At-20) levou grande vantagem quanto à produção de esporos, principalmente em comparação com 3 isolados re sistentes ao benomyl (Tabela 7). Assim, em todas as repetições, Mor At-20 apresentou nümero mais elevado de esporos em comparação com os isolados resistentes, o que consequentemente fez com que tivesse a maior média em relação ao nümero de esporos/placa, presente nas värias repetições.

Com referência aos isolados resistentes, observou-se uma certa oscilação quanto à frequência de esporos, havendo muitas vezes consideräveis diferenças no nümero de esporos produzidos, tanto entre os diferentes isolados, como nas värias repetições de cada um deles. Desta forma, verificou-se que o isolado Mor At-9 apresentou nümero bem baixo de esporos em comparaçäo com os demais isolados resistentes, em contraste com Mor At-10, o qual alēm de sobrepujar os outros resistentes, teve una contagem de esporos bastante significativa. 
Tabela 7. Capacidade de esporulação de quatro isolados benomyl-resistentes em comparação com um benomy - sensivel de Botrytis cinerea, em meio de BDA

\begin{tabular}{|c|c|c|c|c|c|c|}
\hline \multirow{2}{*}{ Isolados } & \multicolumn{5}{|c|}{ no de esporos $\left(\times 10^{6}\right) / \mathrm{placa}$ a/ nas repetições } & \multirow{2}{*}{ Mēdia } \\
\hline & 1. & 2 & 3 & 4 & 5 & \\
\hline Mor At-5 (R) & 136,00 & 107,00 & 144,84 & 110,00 & 44,29 & $108,42 b$ \\
\hline Mor At -7 (R) & 63,00 & 137,50 & 116,65 & 89,50 & 32,64 & $87,85 b$ \\
\hline Mor At-9 (R) & 41,00 & 71,50 & 181,50 & 46,00 & 46,00 & $77,20 b$ \\
\hline Mor At-10 (R) & 120,00 & 159,50 & 185,00 & 159,50 & 124,50 & $149,70 \mathrm{ab}$ \\
\hline Mor At-20 (S) & 216,50 & 181,50 & 186,00 & 190,50 & 186,00 & $192,10 \mathrm{a}$ \\
\hline
\end{tabular}

a/ Aos oito dias de idade das culturas. Médias seguidas pela mesma letra, näo diferem entre si pelo teste de Tukey a $5 \%$.

$(R)$ : isolado resistente a benomyl

(S): isolado sensivel a benomyl 
4.5. Sensibilidade Colateral in vitro de Quatro Isolados de Botrytis cinerea Resistentes e Um Sensivel ao Benomyl, a Quatro Fungicidas

Confirmando os resultados anteriores, constatou-se que em meío de cultura isento de fungicida, o isolado sensível Mor At-20 apresentou crescimento micelial um pouco mais intenso do que os 4 resis tentes ao benomyl, em pelo menos dois ensaios. Alëm disso, foi observado um certo aumento de sensibilidade em relação aos 4 fungicidas testados, por parte dos isolados resistentes, devido à resistência ao benomyl. Assim, notou-se que em todas as concentrações de captafol, o isolado sensivel mostrou uma certa tendência a um desenvolvimento mais acentuado em comparação com os 4 resistentes, o que se tornou mais evidente nas dosagens de 1 a $10 \mathrm{ppm}$ de captan. E mesmo nas concentrações mais elevadas (de 100 e 1000ppm) deste ültimo fungicida, a colônia de Mor At-20 teve diâmetro maior do que a de 3 isolados resistentes, só sendo superada por Mor At -5 .

Com os outros 2 fungicidas, essa propensão a um crescimento mais acentuado por parte do isolado sensivel, foi verificada em relação a apenas alguns isolados resistentes e mesmo assim, com pouca evidência.

Quanto ao desempenho dos 4 fungicidas testados, verificou-se que os que manifestaram melhor eficiência, pelo menos in vitro, no controle de Botrytis einerea foram os dicarboximidas iprodione e pro cymidone, pois todos os isolados foram totalmente inibidos $\mathrm{jä}$ a $10 \mathrm{ppm}$ de procymidone e a 100ppm de iprodione (Tabelas 8, 9, 10 e 11). 
Tabela 8. Crescimento micelial de cinco isolados de Botrytis einerea aos quatro dias de incubação, em meio de cultura de BDA contendo diferentes concentraçöes de captafol

\begin{tabular}{|c|c|c|c|c|c|c|}
\hline \multirow[t]{2}{*}{ Isolados } & \multicolumn{5}{|c|}{$\begin{array}{c}\text { Crescimento diametral das colônias (em } \mathrm{cm} \text { ) a } \\
\text { nas concentraçôs de captafol indicadas } \\
(\text { em ppm) }\end{array}$} & \multirow[t]{2}{*}{ Média } \\
\hline & 0 & 1,0 & 10,0 & 100,0 & 1000,0 & \\
\hline Mor At -5 (R) & $\begin{array}{c}7,55 \mathrm{a} \\
\mathrm{A}\end{array}$ & $\begin{array}{c}7,70 a \\
A\end{array}$ & $\begin{array}{c}1,23 a \\
B\end{array}$ & $\begin{array}{c}0,93 a \\
B\end{array}$ & $\begin{array}{c}1,10 a \\
B\end{array}$ & $3,70 a$ \\
\hline Mor At-7 (R) & $\begin{array}{c}2,16 b \\
A\end{array}$ & $\begin{array}{c}1,58 \mathrm{c} \\
\mathrm{AB}\end{array}$ & $\begin{array}{c}0,36 a \\
B\end{array}$ & $\begin{array}{c}0,26 a \\
B\end{array}$ & $\begin{array}{c}0,21 a \\
B\end{array}$ & $0,91 \mathrm{c}$ \\
\hline Mor $A t-9$ (R) & $\begin{array}{c}7,25 \mathrm{a} \\
\mathrm{A}\end{array}$ & $\begin{array}{c}6,93 \mathrm{a} \\
\mathrm{A}\end{array}$ & $\begin{array}{c}1,28 \mathrm{a} \\
\mathrm{B}\end{array}$ & $\begin{array}{c}0,90 \mathrm{a} \\
\mathrm{B}\end{array}$ & $\begin{array}{c}1,08 a \\
B\end{array}$ & $3,48 a$ \\
\hline Mor At -10 (R) & $\begin{array}{c}3,33 \mathrm{~b} \\
\mathrm{~A}\end{array}$ & $\begin{array}{c}4,11 b \\
A\end{array}$ & $\begin{array}{c}0,50 \mathrm{a} \\
\mathrm{B}\end{array}$ & $\begin{array}{c}0,45 a \\
B\end{array}$ & $\begin{array}{c}0,35 a \\
B\end{array}$ & $1,74 \mathrm{~b}$ \\
\hline Mor At-20 (S) & $\begin{array}{c}7,70 \mathrm{a} \\
\mathrm{A}\end{array}$ & $\begin{array}{c}7,71 \mathrm{a} \\
\mathrm{A}\end{array}$ & $\underset{B}{1,71 a}$ & $\begin{array}{c}1,08 a \\
B\end{array}$ & $\begin{array}{c}1,66 \mathrm{a} \\
\mathrm{B}\end{array}$ & $3,97 a$ \\
\hline Média & $\begin{array}{c}5,59 \\
A\end{array}$ & $\begin{array}{c}5,60 \\
\mathrm{~A}\end{array}$ & $\begin{array}{c}1,01 \\
B\end{array}$ & $\begin{array}{c}0,72 \\
B\end{array}$ & $\begin{array}{c}0,88 \\
B\end{array}$ & \\
\hline
\end{tabular}

a/ Média de três repetiçōes, sendo que cada placa foi inoculada com um disco de micélio de $0,7 \mathrm{~cm}$ de diāmetro. Avaliação no quarto dia apös a inoculação. Médias seguidas pela mesma letra, minúsculas nas colunas e maiūsculas nas linhas, năo diferem entre si pelo teste de Tukey a $5 \%$.

(R): isolado resistente a benomyl

(S): isolado sensivel a benomyl 
Tabela 9. Crescimento micelial de cinco isolados de Botrytis cinerea aos quatro dias de incubação, em meio de cultura de BDA contendo diferentes concentraçöes de iprodione

\begin{tabular}{|c|c|c|c|c|c|c|}
\hline \multirow[t]{2}{*}{ Isolados } & \multicolumn{5}{|c|}{$\begin{array}{c}\text { Crescimento diametral das colônias (em } \mathrm{cm}) \text { a } \\
\text { nas concentraçoes de iprodione indicadas } \\
(\mathrm{em} \mathrm{ppm})\end{array}$} & \multirow[t]{2}{*}{ Média } \\
\hline & 0 & 1,0 & 10,0 & 100,0 & 1000,0 & \\
\hline Mor At $-5 \quad(R)$ & $\begin{array}{c}7,86 a \\
A\end{array}$ & $\begin{array}{c}2,28 a \\
B\end{array}$ & $\begin{array}{c}0,25 \mathrm{a} \\
\mathrm{C}\end{array}$ & $\begin{array}{l}0 \\
\mathrm{C}\end{array}$ & $\begin{array}{l}0 \\
\mathrm{C}\end{array}$ & $2,07 \mathrm{a}$ \\
\hline Mor At -7 (R) & $\begin{array}{c}3,86 \mathrm{c} \\
\mathrm{A}\end{array}$ & $\begin{array}{c}0,80 \mathrm{c} \\
\mathrm{B}\end{array}$ & $\begin{array}{c}0,31 \mathrm{a} \\
B\end{array}$ & $\begin{array}{l}0 \\
B\end{array}$ & $\begin{array}{l}0 \\
\mathrm{~B}\end{array}$ & $0,99 b$ \\
\hline Mor At-9 (R) & $\begin{array}{c}7,03 a \\
A\end{array}$ & $\begin{array}{c}1,70 a b \\
B\end{array}$ & $\begin{array}{c}0,38 a \\
C\end{array}$ & $\begin{array}{l}0 \\
\mathrm{C}\end{array}$ & $\begin{array}{l}0 \\
\mathrm{C}\end{array}$ & $1,82 \mathrm{a}$ \\
\hline Mor $A t-10(R)$ & $\begin{array}{c}5,38 b \\
A\end{array}$ & $\begin{array}{c}1,25 b c \\
B\end{array}$ & $\begin{array}{c}0,2 \mathrm{la} \\
\mathrm{C}\end{array}$ & $\begin{array}{l}0 \\
\mathrm{C}\end{array}$ & $\begin{array}{l}0 \\
\mathrm{C}\end{array}$ & $1,36 \mathrm{~b}$ \\
\hline Mor At-20 (S) & $\begin{array}{c}7,76 a \\
A\end{array}$ & $\begin{array}{c}1,65 a b \\
B\end{array}$ & $\begin{array}{c}0,33 a \\
c\end{array}$ & $\begin{array}{l}0 \\
\mathrm{C}\end{array}$ & $\begin{array}{l}0 \\
C\end{array}$ & $1,94 \mathrm{a}$ \\
\hline Média & $\begin{array}{c}6,37 \\
A\end{array}$ & $\begin{array}{c}1,53 \\
B\end{array}$ & $\begin{array}{c}0,29 \\
C\end{array}$ & $\begin{array}{l}0 \\
\mathrm{C}\end{array}$ & $\begin{array}{l}0 \\
\mathrm{C}\end{array}$ & \\
\hline
\end{tabular}

al Média de três repetições, sendo que cada placa foi inoculada com um disco de micélio de $0,7 \mathrm{~cm}$ de diâmetro. Avaliação no quarto dia após a inoculação. Médias seguidas pela mesma letra, minúsculas nas colunas e maiüsculas nas linhas, não diferem entre si pelo teste de Tukey a $5 \%$.

(R): isolado resistente a benomyl.

(S): isolado sensível a benomyl 
Tabela 10. Crescimento micelial de cinco isolados de Botmytis cinerea aos quatro dias de incubação, em meio de cultura de BDA contendo diferentes concentraçöes de captan

\begin{tabular}{|c|c|c|c|c|c|c|}
\hline \multirow[t]{2}{*}{ Isolados } & \multicolumn{5}{|c|}{$\begin{array}{c}\text { Crescimento diametral das colônias (em } \mathrm{cm} \text { ) } \text { a/ } \\
\text { nas concentraçóes de captan indicadas } \\
(\text { em ppm) }\end{array}$} & \multirow[t]{2}{*}{ Média } \\
\hline & 0 & 1,0 & 10,0 & 100,0 & 1000,0 & \\
\hline Mor At-5 (R) & $\begin{array}{c}6,33 a \\
A\end{array}$ & $\begin{array}{c}4,86 a b \\
A\end{array}$ & $\underset{A}{5,11 a b}$ & $\begin{array}{c}6,28 \mathrm{a} \\
\mathrm{A}\end{array}$ & $\begin{array}{c}0,55 \mathrm{a} \\
\mathrm{B}\end{array}$ & $4,62 \mathrm{a}$ \\
\hline Mor At -7 (R) & $\begin{array}{c}4,1.1 \mathrm{~b} \\
\mathrm{~A}\end{array}$ & $\begin{array}{c}3,95 \mathrm{bc} \\
\mathrm{A}\end{array}$ & $\begin{array}{c}3,90 b c \\
A\end{array}$ & $\begin{array}{c}3,90 b c \\
A\end{array}$ & $\begin{array}{c}0,23 a \\
B\end{array}$ & $3,21 b$ \\
\hline Mor At-9 (R) & $\begin{array}{c}3,81 b \\
A\end{array}$ & $\begin{array}{c}3,10 b c \\
A\end{array}$ & $\begin{array}{c}1,88 C \\
A B\end{array}$ & $\begin{array}{c}2,48 c \\
A\end{array}$ & $\begin{array}{c}0,11 \mathrm{a} \\
\mathrm{B}\end{array}$ & $2,27 c$ \\
\hline Mor $A t-10 \quad(R)$ & $\begin{array}{c}3,48 b \\
A B\end{array}$ & $\begin{array}{c}2,83 c \\
B\end{array}$ & $\begin{array}{c}5,25 a b \\
A\end{array}$ & $\begin{array}{c}4,91 \mathrm{ab} \\
\mathrm{A}\end{array}$ & $\begin{array}{c}0,26 a \\
C\end{array}$ & $3,34 b$ \\
\hline Mor At-20 (S) & $\begin{array}{c}6,28 \mathrm{a} \\
\mathrm{A}\end{array}$ & $\begin{array}{c}6,18 \mathrm{a} \\
\mathrm{A}\end{array}$ & $\begin{array}{c}6,03 a \\
A\end{array}$ & $\begin{array}{c}6,00 \mathrm{a} \\
\mathrm{A}\end{array}$ & $\begin{array}{c}0,46 a \\
B\end{array}$ & $4,99 a$ \\
\hline Média & $\begin{array}{c}4,80 \\
A\end{array}$ & $\begin{array}{c}4,18 \\
A\end{array}$ & $\begin{array}{c}4,43 \\
A\end{array}$ & $\begin{array}{c}4,71 \\
A\end{array}$ & $\begin{array}{c}0,32 \\
B\end{array}$ & \\
\hline
\end{tabular}

a/ Média de três repetições, sendo que cada placa foi inoculada com um disco de micélio de $0,7 \mathrm{~cm}$ de diâmetro. Avaliação no quarto dia após a inoculação. Médias seguidas pela mesma letra, minúsculas nas colunas e maiūsculas nas linhas, năo diferem entre si pelo teste de Tukey a $5 \%$.

(R): isolado resistente a benomyl

(S): isolado sensïvel a benomyl. 
Tabela 11. Crescimento micelial de cinco isolados de Botrytis cinerea aos quatro dias de incubação, em meio de cultura de BDA contendo diferentes concentrações de procymidone

\begin{tabular}{|c|c|c|c|c|c|c|}
\hline \multirow[t]{2}{*}{ Isolados } & \multicolumn{5}{|c|}{$\begin{array}{c}\text { Crescimento diametral das colônias (em cm) al } \\
\text { nas concentraçöes de procymidone indi- } \\
\text { cadas (emppm) }\end{array}$} & \multirow[t]{2}{*}{ Média } \\
\hline & 0 & 1,0 & 10,0 & 100,0 & 1000,0 & \\
\hline \multirow[t]{2}{*}{ Mor At -5 (R) } & $7,95 a$ & $0,55 a$ & 0 & 0 & 0 & \multirow[t]{2}{*}{$1,70 \mathrm{a}$} \\
\hline & A & B & B & B & B & \\
\hline \multirow[t]{2}{*}{ Mor At -7 (R) } & $5,75 c$ & $0,28 a$ & 0 & 0 & 0 & \multirow[t]{2}{*}{$1,20 b$} \\
\hline & $\mathrm{A}$ & B & B & B & B & \\
\hline \multirow[t]{2}{*}{ Mor At-9 (R) } & $6,60 b$ & $0,35 \mathrm{a}$ & 0 & 0 & 0 & \multirow[t]{2}{*}{$1,39 b$} \\
\hline & A & B & B & B & B & \\
\hline \multirow[t]{2}{*}{ Mor At-10 (R) } & $6,98 b$ & $0,36 \mathrm{a}$ & D & 0 & 0 & \multirow[t]{2}{*}{$1,46 a t$} \\
\hline & A & B & B & B & B & \\
\hline \multirow[t]{2}{*}{ Mor At -20 (S) } & $8,18 a$ & $0,51 \mathrm{a}$ & 0 & 0 & 0 & \multirow[t]{2}{*}{$1,73 a$} \\
\hline & A & B & B & B & B & \\
\hline \multirow[t]{2}{*}{ Média } & 7,09 & 0,41 & 0 & 0 & 0 & \\
\hline & A & B & C & C & C & \\
\hline
\end{tabular}

a/ Média de três repetições, sendo que cada placa foi inoculada com um disco de micélio de 0,7crn de diâmetro. Avaliação no quarto dia apôs a inoculação. Médias seguidas pela mesma letra, minüsculas nas colunas e maiúsculas nas linhas, não diferem entre si pelo teste de Tukey a $5 \%$.

(R): isolado resistente a benomyl

(S): isolado sensível a benomyl. 
4.6. Competição in vitro entre Um Isolado de Botrytis cinerea Sensivel e Outro Resistente ao Benomyl.

Os dados da Tabela 12 nos mostram que, apesar de se ter empregado uma concentração inicial de esporos bem mais elevada para o isolado resistente em relação ao sensível $\left(53 \times 10^{4}\right.$ esporos/ml para o isolado resistente e $28 \times 10^{4}$ esporos/ml para o isolado sensível), na fase 2 esta situação já estava invertida, devido ao declínio no nümero de esporos do isolado resistente, o qual estava sendo sobrepujado pelo sensivel. Mas da fase 3 em diante, a frequência de esporos do isolado resistente foi ficando cada vez mais alta, superando a do sensível. Nas duas ültimas fases, foi constatado um nümero bem mais elevado de esporos nas placas contendo BDA suplementado com $100 \mathrm{ppm}$ de benomyl do que naquelas contendo somente BDA, razão pela qual tornou-se impossível fazer uma avaliação do nümero de esporos resistentes e sensíveis. 
Tabela 12. Efeito da competição em meio de cultura na frequência relativa de isolados de Botrytis cinerea resistente e sensível ao fungicida benomy 1

\begin{tabular}{|c|c|c|c|c|}
\hline \multirow{3}{*}{$\begin{array}{l}\text { Fases do ex- } \\
\text { perimento }\end{array}$} & \multicolumn{4}{|c|}{$\begin{array}{l}\text { no a/e \% de esporos ou de colônias de isolados de } B \text {. } \\
\text { cinerea resistente (R) e sensivel (S) ao benomyl }\end{array}$} \\
\hline & \multicolumn{2}{|c|}{ n! } & \multicolumn{2}{|c|}{$\%$} \\
\hline & $\mathrm{R}$ & S & $\mathrm{R}$ & S \\
\hline 0 b / & 53 & 28 & 65,44 & 34,56 \\
\hline 1 & 172 & 53 & 76,45 & 23,55 \\
\hline 2 & 43 & 61 & 41,34 & 58,66 \\
\hline 3 & 157 & 69 & 69,47 & 30,53 \\
\hline
\end{tabular}

al Total de contagem em diluição e nọ de placas variäveis, mas constante dentro da mesma fase.

b/ os nọ da fase 0 correspondem a estimativas de hemocitômetro (no $\times 10^{4}$ conidios/ml). 


\section{DISCUSS $\widetilde{O} O$}

Relatos de literatura evidenciam o fato de que o uso contínuo de um único fungicida seletivo ou fungicidas seletivos pertencentes ao mesmo grupo de resistência cruzada, poderá promover o desenvolvimento de linhagens de fungos resistentes a ele(s) (DEKKER, 1977; 1981; UESUGI, 1978; DELP, 1980). Assim, a descoberta de que os 3 isolados de Botrytis cinerea obtidos em 1978, de frutos de morango procedentes de Atibaia (Mor At-1, Mor At-2 e Mor At-3), se mostraram resistentes ao benomyl não foi inesperada, desde que este produto vinha sendo aplicado em condições de campo, no estado de São Paulo, a partir de 1969 (REMIRO e KIMATI, 1974).

Por outro lado, a constatação de que os isolados Donner, Torrey e SH-2 foram sensíveis ao benomyl, apesar dos frutos terem sido pulverizados com este fungicida, pode ser explicada com base na procedência dos morangos a partir dos quais tais isolados foram obtidos (plan tas de estufa do IAC-Instituto Agronômico de Campinas). Na situação des te estabelecimento, o principal objetivo é se obter mudas sadias, livres 
de virus, não havendo maiores preocupações no sentido de se manter os frutos totalmente isentos de doenças, já que eles não vão ser comercializados. Assim, as aplicações de benomyl não são tão constantes, havendo intervalos de pulverizações relativamente longos. Nestas condições de baixa pressäo de seleção, mesmo que linhagens resistentes tenham chan ce de se desenvolverem durante os períodos de aplicação do produto, nos intervalos das pulverizações, de acordo com DEKKER (1981), as formas sen síveis do patógeno podem competir com as resistentes, e a populaçăo tem então a oportunidade de retornar ao equilíbrio, voltando predominantemente a ser sensỉvel. Em relação a esse fenômeno, GEORGopoulos

já havia salientado que quanto maior a pressão de seleção, mais rápida serā a mudança da população sensỉvel em direção à resistente. Uma maior frequência de aplicações do produto implica em um maior tempo de exposição à droga, favorecendo a proliferação das formas resistentes. Um caso interessante que pode bem ilustrar esta situação foi verificado na Grécia, onde a frequência de uma linhagem benomyl-resistente de Cercospora beticola aumentou de 3,5\% para 91,5\%, com apenas duas aplicações do fungicida em um mês (DOVAS et alii, 1976). Em relação a esse fenômeno, HISADA et alii (1981) também obtiveram resultados semelhantes, sobre o efeito da pressão de seleção sobre os mutantes resistentes.

Embora 9 isolados resistentes ao benomyl, tenham sido provenientes de frutos que não foram tratados com este fungicida, tal in formação, obtida de lavrador, provavelmente estava incorreta. Os resultados obtidos sugerem que o fungicida benomyl deve ter sido empregado na cultura de morango a partir da qual tais isolados foram conseguidos. 
A justificativa para tal afirmação está baseada no fato de que, se foram encontrados isolados de $B$. cinerea resistentes ao benomyl, isto é sinal de que os mesmos já haviam tido contacto com este produto anteriormente, pois só assim é que haveria possibilidade de serem selecionados isolados resistentes a ele. Pois graças à pressão de seleção exercida pelo fungicida é que as formas sensiveis são eliminadas, enquanto que as resistentes são selecionadas e têm a chance de se desenvolver. Se benomyl nunca tivesse sido aplicado nesta cultura, logicamente isolados resistentes seriam muito mais difíceis de serem encontrados, pois mesmo que linhagens resistentes surgissem espontaneamente em meio à população sensível do fungo, elas seriam provavelmente logo sobrepujadas pelas originais, fazendo valer os preceitos da seleção natural. Além disso, na ausência de um agente seletivo, segunco DELP (1980), os mutantes podem aparecer naturalmente, mas a uma frequência muito baixa, provavelmente menos do que 1 propágulo em $10^{8}$. E desde que formas resistentes raramente apresentam uma vantagem adaptativa sobre as selvagens, elas não têm nenhuma chance de se desenvolverem a ponto de atingirem números detectáveis. E mesmo que possuam adaptabilidade igual a das sensíveis, elas não alcançarão números elevados na população, a menos que frequentes aplicaçoes do fungicida, permitam que tal fato aconteça. Por outro lado, não se pode descartar a possibilidade de esporos resistentes a benomyl, provenientes de culturas vizinhas onde este fungicida estava sendo aplicado, tenham alcançado o local em que se encontravam os morangos considerados 
Em vista destas argumentações, é evidente que a constatação de que os isolados Mor Pira-1 até Mor Pira-21 foram todos sensíveis a benomyl, já era praticamente esperada, desde que os frutos não ha viam sido tratados com este fungicida.

Em relação aos isolados Botr-Pied e Mor Val-1 atē Mor Val-7, sobre os quais não foi possível se obter informações sobre os tratamentos recebidos, desde que tais isolados foram todos sensíveis ao benomyl, pode-se alegar duas hipóteses. Assim, como eles foram originários de cultura comercial de morango, ou os frutos não foram tratados com o referido fungicida, ou então as aplicações do mesmo não foram muito frequentes, propiciando, desta forma, uma baixa pressão de seleçäo, a qual não foi suficiente para promover o desenvolvimento dos mutantes resistentes que porventura possam ter aparecido.

Vārios autores têm relatado a ocorrência de linhagens de fungos resistentes a altos níveis de fungicidas sistêmicos, principalmente o benomyl. Assim, os mutantes benomyl-resistentes de $B$. cinerea isolados por BOLLEN e SCHOLTEN (1971), mesmo a $1000 \mathrm{ppm}$ de benomyl não apresentaram completa inibição no crescimento, enquanto que o tipo selvagem foi eliminado a $0,5 \mathrm{ppm}$ do produto, no meio. Resultados semelhantes foram obtidos com linhagens benomyl-resistentes de Sphaerotheca fuZiginea (DEKKER, 1977), ao passo que as formas resistentes de Mycosphaerelza fragariae, obtidas por REMIRO e KIMATI (1974), suportaram até $100 \mathrm{ppm}$ do referido fungicida e a forma sensível, lppm. Já em relação a outro fungicida do mesmo grupo, tiofanato-metílico, IIDA (1975) observou a presença de isolados de Venturia inaequalis que resistiram 
aite 1000 ppm, sendo que a forma sensível foi inibida a 10ppm deste fungicida. Portanto, a constatação de que 4 isolados resistentes de $B$. cinerea alcançaram um grau de resistência tão elevado, ou seja, 1000ppm de benomyl, é mais um caso que se acrescenta aos jā mencionados.

Desde que a dose de benomyl recomendada para aplicações em condições de campo, é de 350ppm, a presença de linhagens de B. cinerea resistentes a $100 \mathrm{ppm}$ deste produto não causaria maiores problemas, mas a ocorrência de formas resistentes a $1000 \mathrm{ppm}$ realmente implicaria em faThas no controle. Acontece que muitas vezes são empregadas dosagens de atē 1000 ppm ou mais deste fungicida, e sendo assim, tambēm não haveria motivo para se preocupar com os mutantes que resistem até $1000 \mathrm{ppm}$ do pro duto. $\bar{A}$ primeira vista, $\bar{e}$ provavelmente assim que se vería a situação. Mas, analisando mais profundamente, pode-se concluir que, se tais mutantes resistentes chegaram a atingir um nível tão alto de resistência, foi justamente devido à elevada pressão de seleção (dosagens de 1000 ppm ou mais) imposta a eles. Mas tal fato não ocorreu subitamente. Segundo DEKKER (1982a) e BEEVER e BRIEN (1983), s b os efeitos de uma constante pressão de seleção, as linhagens resistentes que porventura tenham um baixo nível de resistência, em consequência do longo tempo de exposição ao fungicida, poderiam, eventualmente, atravês de trocas genéticas, adquirır uma melhor adaptabilidade e um aumento n• grau de resistência. A aquisiçao de um nível tão alto de resistência ao benomyl (1000ppm) pelos 4 isolados de $B$. cinerea testados, provavelmente deve ter ocorrido desta maneira. 
Com base nestas argumentações, poderíamos atē questionar se, com dosagens ainda mais altas de benomyl, não estaríamos forçando o desenvolvimento de mutantes ainda mais "aperfeiçoados", com grau de resistência e adaptabilidade ainda mais elevados.

A adaptabilidade de mutantes resistentes a drogas, comparada com aquela da linhagem selvagem do fungo, é um fator primordial para a sobrevivência e estabelecimento de uma população de patógenos resistentes. Nas condições dos experimentos realizados observou-se que, de uma forma geral, houve uma vantagem adaptativa do isolado sensível de $B$. cinerea (Mor At-20) em relação aos 4 resistentes ao benomyl (Mor At-5, Mor At-7, Mor At-9 e Mor At-10), quando em meio sem fungicida, pelo menos em relação a um ou dcis dos parâmetros analisados (crescimento micelial e esporulação em meio de BDA). Tais resultados confirmam mais uma vez o fato de que a aquisição de resistência a drogas, geralmente traz como consequência uma menor competitividade para os mutantes que se tornam resistentes a elas, pois, de acordo com DELP (1980), tais mutantes raramente têm uma vantagem adaptativa sobre as formas selvagens. Neste sentido, um dos fatores que contribuem para essa menor adaptabilidade dos mutantes é a alteração na taxa de crescimento, quando comparada com a de suas formas originais sensiveis. Como regra geral, na ausência da droga, essa alteração implica numa menor taxa de crescimento para os mutantes resistentes, havendo, portanto, vantagem seletiva para os indivíduos sensíveis que, apōs algum tempo, acabarão sobrepujando os resistentes (GURGEL e AZEVEDO, 1969). Assim, em experimentos de competição onde se utilizou uma mistura de esporos de B.einerea sensiveis 
e resistentes aos dicarboximidas, GULLINO e GARIBALDI (1981) inoculando em meio de cultura isento de fungicida, e HISADA et alii (1981) inoculan do em plantas, constataram depois de um certo tempo, o desaparecimento dos mutantes resistentes. Tais resultados concordam com o que ocorreu durante os experimentos de competição a que foram submetidos o isolado sensível (SH-2) e o resistente ao benomyl (Mor At-1), pelo menos até a fase 2. Desta forma, mesmo empregando-se uma concentração inicial de esporos bem maior para o isolado resistente do que para o sensível veri ficou-se que, até a fase 2, houve uma vantagem seletiva para as formas selvagens, as quais sobrepujaram as resistentes. No entanto, a partir daí ocorreu o inverso, ou seja, houve predominância das formas resistentes, numa indicação de que estas são iguais ou mais competitivas do que as sensíveis (BERGAMIN et alii, 1975) ou que convivem heterocarioticamente com as sensïveis (DEKKER, 1982b).

Os ensaios conduzidos por PANAGIOTAKU e MALATHRAKIS (1981) também demonstraram uma menor adaptabilidade das formas resistentes, jä que o crescimento das linhagens dicarboximida-resistentes de $B$. cinerea em meio de BDA, foi mais lento do que o das linhagens sensíveis do fungo.

O prejuizo das formas resistentes a fungicidas também pode ser traduzido em termos de menor produção de esporos, como foi verificado com mutantes de Cladosporium cucumerinum e Fusarium oxysporum f. sp. narcissi, resistentes a pimaricin (DEKKER, 1982a) e mutantes de Monilinia laxa resistentes a benomyl (OCAWA et alii, 1984). Entretanto, outros autores relatam a ocorrência de formas resistentes aos benzimi- 
dazóis, que mostraram possuir adaptabilidade igual a das originais sen siveis em Penicillium digitatum (WILD e RIPPON, 1975); Cercospora beticola (RUPPEL, 1975; DOVAS et alii, 1976); Sphaerotheca fuliginea (SCHEPERS, 1984).

De acordo com BÉRGAMIN et alii (1975), as diferenças nas taxas de crescimento dos vários mutantes resistentes a drogas, podem ser explicadasem termos da importância do gene mutado. Assim, considerando-se que o gene que confere resistência à droga não foi adicionado ao cromossomo do microorganismo e sim que provēm de uma mutação num gene preexistente o qual, a partir do momento em que se deu a mutação, deixou de executar sua antiga função, para desempenhar outra, a taxa de crescimento do mutante poderá ser reduzida ou não, dependendo da importância do gene mutado. Desta forma, se aquele gene preexistente, que foi alterado pela mutação, controlasse uma importante função no metabolismo do microorganismo, o mutante, que não mais o possui, terā sua taxa de crescimento diminuida. Se, porēm, esse gene controlasse uma função secundäria para a cêlula como, por exemplo, sua morfologia, o mutante não terá alterada sua taxa de crescimento. E, se porventura, a mutação para resistência à droga trouxer, como efeito colateral, uma aceleração em algum processo importante para a célula, isto poderá ocasionar, consequentemente, um aumento na taxa de crescimento.

Embora um fungicida dicarboximida (Ronilan), tenha sido empregado nas plantações de morango, não se observou o desenvolvimentode resistência de um alto nível em relação aos dois dicarboximidas testados (procymidone e iprodione). Tais resultados concordam com os obtidos nos 
ensaios conduzidos por BEEVER e BRIEN (1983), onde foi constatada a presença, em condições de campo, de linhagens de $B$. cinerea apresentando baixo nível de resistência aos dicarboximidas. Alëm disso, dos 4 fungicidas testados, iprodione e procymidone foram os mais eficientes no controle de $B$. cinerea, pois todos os isolados foram completamente inibidos jā a 10ppm de procymidone e a 100ppm de iprodione. Consequentemente, os dicarboximidas poderiam substituir os benzimidazóis onde a ocorrência de linhagens de fungos resistentes a fungicidas deste grupo, tenham causado falhas no controle. Tal sugestão, baseada nos resultados obtidos, tambëm encontra justificativas nas afirmações de BEEVER e BRIEN (1983). Segundo estes autores, duas razões podem ser sugeridas para apontar a diferença na situação entre resistência aos dicarboximidas e aos benzimidazóis. Primeiramente, as linhagens resistentes aos dicarboximidas encontradas no campo, apresentam baixo nível de resistência; a segunda diferença é que enquanto aquisição de resistência aos benzimidazóis não parece conferir qualquer perda de adaptabilidade à linhagem, aquisição de resistência aos dicarboximidas, sim.

Em relação ao fenômeno da sensibilidade colateral, os resultados obtidos não foram tão evidentes como aconteceu em casos jä relatados em literatura, como o de mutantes fosforotiolate-resistentes de Pyricularia oryzae, os quais apresentaram um aumento de sensibilidade a fosforamidates (UESUGI et alii, 1974); o aumento de sensibilidade a zineb por isolados de Verticillium matthousei resistentes a benomyl (LAMBERT e WUEST, 1975); e ainda o aumento de sensibilidade a captan e prochloraz por um isolado benomyl-resistente de Monilinia fructicola

(DIJKHUIZEN 
et alii, 1983). Mesmo assim, nas condições dos experimentos realizados, notou-se que 3 dos 4 isolados benomyl-resistentes, mostraram tendência a serem mais sensíveis do que o isolado benomyl-sensível, aos 4 fungicidas testados (captan, captafol, procymidone e iprodione). 
6. CONCLUSÕES

Do presente trabalho podem ser tiradas as seguintes conclusões:

1. Isolados de Botry \pm is cinerea, agente do mofo cinzento do morango, resistentes ao benomyl, foram obtidos de plantações comerciais de Atibaia.

2. 0 nível de resistência de 4 isolados resistentes foi $\geqslant 1000$ ppm de benomyl.

3. Um isolado sensível apresentou maior vantagem adaptativa, em termos de crescimento micelial e/ou esporulação em meio de BDA, em relação a 4 isolados resistentes ao benomyl.

4. Dos 4 isolados benonyl-resistentes, 3 mostraram tendên cia a serem mais sensíveis do que um isolado benomyl-sensível, aos fungicidas captan, captafol, procymidone e iprodione. 
5. Todos isolados testados, incluindo 4 resistentes e 1 sensivel a benomyl, continuam altamente sensíveis aos fungicidas procymidone e iprodione. 
LITERATURA CITADA

BEEVER, R.E. e R.J.W.BYRDE, 1982. Resistance to the dicarboximide fungicides. In: DEKKER, J. e S.G.GEORGOPOULOS,Eds. Fungicide resistance in crop protection. Wageningen, Centre for Agricultural Publishing and Documentation, p.101-117.

BEEVER, R.E. e H.M.R.BRIEN, 1983. A survey of resistance to the dicarboximide fungicides in Botrytis cinerea. New Zealand Jom nal of Agricultural Research. Wellington, 26(3):391-400.

BERGAMIN FILHO, A.; H.KIMATI e J.L.AZEVEDO, 1975. O conceito de força de drogas. Summa Phytopathologica. Piracicaba, 1(1):31-42.

BIER, 0., 1965. Bacteriologia e Imunologia. 12 a ed. São Paulo, Ed.Me1horamentos, $983 \mathrm{p}$.

BOESEWINKEL, H.J., 1976. Storage of fungal cultures in water. Transactions of the British Mycological Society. London, 66:183-185.

BOLLEN, G.J. e G.SCHOLTEN, 1971. Acquired resistance to benomyl and some other systemic fungicides in a strain of Botrytis cinerea in cyclamen. Netherlands tournal of plant pathology. Wageningen, 77: 83-90. 
BROWN, A.W.A., 1961. Negatively-correlated insecticides, a possible countermeasure for insecticide resistance. Pest Control. Cleveland, 29(9):24,26,40-42. Apud Biological Abstracts. Philadelphia, 37: 1119,1962 .

BRYSON, V. e W.SZYBALSKI, 1955. Microbial drug resistance. Advances in Genetics. New York, 7:1-46.

CARDOSO, C.0.N., 1980. Doenças do morangueiro - Fragaria vesca. In: GALLI, F., Coord. Manual de Fitopatologia; Doenças das Plantas Cultivadas. Säo Paulo, Ed. Agronôrnica Ceres, v.2, cap.28, p.392-403.

DAVIDSE, L.C., 1982. Benzimidazole compounds: selectivity and resistance. In: DEKKER, J. e S.G. GEORGOPOULOS, Eds. Fungicide resistance in crop protection. Wageningen, Centre for Agricultural Publishing and Documentation, p.60-70.

DEKKER, J., 1976. Acquired resistance to fungicides. Annual Review of Phytopathology. California, 14:405-428.

DEKKER, J., 1977. Resistance. In: MARSH, R.W., Ed. Systemic Fungicides. 2․ ed. London, Longman, cap.9, p.176-197.

DEKKER, J., 1981. Strategies for avoiding resistance to fungicides. In: JENKYN, J.F. e R.T.PLUMB, Eds. Strategies for the Control of cereal disease. Oxford, Blackwell scientific Publication, p.123-133.

DEKKER, J., 1982a. Can we estimate the fungicide-resistance hazard in the field from laboratory and greenhouse tests? In: DEKKER, J. e S. G.GEORGOPOULOS, Eds. Fungicide resistance in crop protection. Wageningen, Centre for Agricultural Publishing and Documentation, p. 128-138. 
DEKKER, J., 1982b. Countermeasures for avoiding fungicide resistance. In: DEKKER, J. e S.G.GEORGOPOULOS, Eds. Fungicide resistance in crop protection. Wageningen, Centre for Agricultural Publishing and Documentation, p.177-186.

DELP, C.J., 1980. Coping with resistance to plant disease control agents. Plant Disease. St.Paul, 64(7):652-658.

DIJKHUIZEN, J.P.; J.M.OGAWA e B.T.MANJI, 1983. Activity of captan and prochloraz on benomyl-sensitive and benomyl-resistant isolates of Monilinia fructicola. Plant Disease. St.Paul, 67(4):407-409.

DOVAS, C.; G.SKYLAKAKIS e S.G.GEORGOPOULOS, 1976. The adaptability of the benomyl-resistant population of Cercospora beticola in northern Greece. Phytopathology. Lancaster, 66:1452-1456.

EDGINGTON, L.V.; K.L.KHEW e G.L.BARRON, 1971. Fungitoxic spectrum of benzimidazole compounds. Phytopathology. Lancaster, 61:42-44.

FIGUE IREDO, M.B., 1967. Estudos sobre a aplicação do método de Castellani para conservação de fungos patógenos em plantas. O Biológico. São Paulo, 33:9-13.

FIGUEIREDO, M.B., 1971. Resenha de dados obtidos sobre o método de prẹ servação de fungos em água destilada. Revista da Sociedade Brasilei ra de Fitopatologia. Mossoró, 4(4):89-91.

FIGUE IREDO, M.B. e C.P.V.PIMENTEL, 1975. Métodos utilizados para conservação de fungos na Micoteca da Seção de Micologia Fitopatológica do Instituto Biológico. Sumor Phytopathologica. Piracicaba, 1(4): 299-302. 
$x$

FLETCHER, J.T. e M.J.GRIFFIN, 1981. The sensitivity of populations of Erysiphe graminis to triadimefon and Botrytis cinerea to iprodione. Netherlands joumal of plant pathology. Wageningen, 87(6):239.

GEORGOPOULOS, S.G., 1969. The problem of fungicide resistance. Bio Science. Washington, 19(11):971-973.

GEORGOPOULOS, S.G., 1977. Pathogens become resistant to chemicals. In: HORSFALL, J.G. e E.B.COWLING, Eds. Plant Disease; an advanced treatise. New York, Academic Press, v.1, p.327-345.

GEORGOPOULOS, S.G., 1982. Cross-resistance. In: DEKKER, J. e S.G. GEORGOPOULOS, Eds. Fungicide resistance in crop protection. Wageningen, Centre for Agricultural Publishing and Documentation, p. 53-59.

GEORGOPOULOS, S.G. e C.ZARACOVITIS, 1967. Tolerance of fungi to organic fungicides. Annual Review of Phytopathology. California, 5:109-130.

GULlino, M.L. e A.GARIBALDI, 1981. Competition in vitro and in vivo between strains of Botrytis cinerea Pers. sensitive and resistant to dicarboximides. Netherlands journal of plant pathology. Wageningen, $87(6): 243$.

GURGEL, J.T.A. e J.L.AZEVEDO, 1969. Resistência de microorganismos aos antibiōticos. In: LACAZ, C.S. Antibiö́ticos. 2a ed. São Paulo, Ed. Sarvier, p.322-347.

HARTILL, W.F.T.; G.R.TOMPKINS e P.J.KLEINSMAN, 1983. Development in New Zealand of resistance to dicarboximide fungicides in Botrytis cinerea, to acylalinines in Phytophthora infestans, and to guazatine in Penicillium italicum. New Zealand journal of Agricultural Research. Wellington, 26(2):261-269. 
HECKLY, R.J., 1978. Preservation of microorganisms. Advances in Applied Microbiology. New York, 24:1-53.

HISADA, Y.; H.TAKAKI; T.KATO; T.OZAKI e Y.KAWASE, 1981. Fitness of procymidone-resistant Botrytis cinerea strains developed in vitro. Netherlands journal of plant pathology. Wageningen, 8?(6):243-244.

IIDA, W., 1975. On the tolerance of plant pathogenic fungi and bacteria to fungicides in Japan. Japan Pesticide Information. Tokyo, 23:1316 .

KATAN, T., 1981. Resistance to dicarboximide fungicides in Botrytis cintrea from cucumbers, tomatoes, strawberries and roses. Netherlands journal of plant pathology. Wageningen, $87(6): 244$.

KATAN, T., 1982. Persistence of dicarboximide-fungicide resistance in populations of Botrytis cinerea in a warm, dry temperate agroclimate. Phytoparasitica, Bert Dagan, 10(3):209-211.

KIMATI, H., 1978. Fungicidas. In: GALLI, F., Coord. Manual de Eitopatologia; Principios e Conceitos. São Paulo, Ed. Agronômica Ceres. v.1, cap.18, p.325-373.

KIRBY, A.H.M., 1972. Progress towards systemic fungicides. PANS. London, 18(1):1-33.

KURAMOTO, T., 1976. Resistance to benomyl and thiophanate-methyl in strains of Penicillium digitatum and $P$. italicum in Japan. Plant Disease Reporter. Washington, 60(2):168-172.

LAMBERT, D.H. e P.J.WUEST, 1975. Increased sensitivity to zineb for Verticizlizm malthousei strains tolerant to benomy1. Phytopathology. Lancaster, 65:637-638. 
LEBEN, C.; D.M.BOONE e G.W.KEITT, 1955. Venturia inaequalis (Cke.) Wint. IX Search for mutants resistant to fungicides. Phytopathology. Lancaster, $45: 467-472$.

LORENZ, G. e E.H.POMMER, 1982. Pectolytic and cellulolytic enzymes of dicarboximide-sensitive and resistant strains of Botrytis cinerea. EPPO Bulletin. 12(2):145-149. Apud Review of plant pathology, Kew, $62(1): 26,1983$.

MENTEN, J.O.M.; C.G.MACHADO; E.MINUSSI; C.CASTRO e H.KIMATI, 1976. Efe to de alguns fungicidas no crescimento micelial de Macrophomina phaseolina (Tass.) Goid. in vitro. Fitopatologia Brasileira. Brasilia, I(2):57-66.

MILLER, M.W. e J.T.FLETCHER, 1974. Benomyl tolerance in Botrytis cinerea isolates from glasshouse crops. Transactions of the British Mycological Society. London, 62:99-103.

NEWTON, B.A., 1965. Mechanisms of antibiotic action. Annual Review of Microbiology. California, 19:209-240.

OGAWA, J.M.; J.D.GILPATRICK e L.CHIARAPPA, 1977. Review of plant pathogens resistant to fungicides and bacteriocines. FAO Plant Protection Bulletin. Rome, 25(3):97-111.

OGAWA, J.M.; B.T.MANJI; R.M.BOSTOCK; V.M.CAÑEZ e E.A.BOSE, 1984 . Detection and Characterization of benomyl-resistant Monilinia laxa on apricots. Plant Disease. St.Paul, 68(1):29-31.

PANAGIOTAKU, M.G. e N.E.MALATHRAKIS, 1981. Resistance of Botrytis cinerea Pers. to dicarboximide fungicides. Netherlands journal of plant pathology. Wageningen, $87(6): 242$. 
PEPIN, H.S. e E.A.MacPHERSON, 1982. Strains of Botrytis cinerea resistant to benomyl and captan in the field. Plant Disease. St. Paul, 66:404-405.

PEREIRA, A.L.G.; A.G.ZAGATTO e M.B.FIGUEIREDO, 1970. Preservação e virulência de bactérias mantidas em āgua destilada. O Biológico. São Paulo, $36: 311-314$.

PESSANHA, B.M.R.; T.IAMAMOTO e H.J.SCARANARI, 1970. Benlate e cercobinfungicidas novos no contrôle das manchas foliares do morangueiro (Fragaria vesca L.). O Biológico. São Paulo, 36(5):121-128.

PIMENTEL, C.P.V.; G.P.B.PITTA e M.B.FIGUEIREDO, 1980. Preservação da patogenicidade de alguns fungos conservados em ägua destilada. 0 Biológico. São Paulo, $46(12): 281-287$.

REMIRO, D. e H.KIMATI, 1974. Resistência a benomyl e tiofanato em Mycosphaerella fragariae (TuI.) Lind. O Biológico. São Paulo, 40 (1) $: 22-24$.

RUPPEL, E.G., 1975. Biology of benomy1-tolerant strains of Cercospora beticola from sugar beet. Phytopathology. Lancaster, 65:785-789.

SCHEPERS, H.T.A.M., 1984. Persistence of resistance to fungicides in Sphaerotheca fuliginea. Netherlands joumal of plant pathology. Wageningen, $90(4): 165-171$.

SCHNITZER, R.J. e E.GRUNBERG, 1957. Drug Resistance of Microorganisms. New York, Academic Press. 395p.

SHABI, E. e T.KATAN, 1979. Genetics, Pathogenicity and stability of carbendazin resistant isolates of Venturia pirina. Phytopathology. Lancaster, 69:267-269. 
SHLRIDAN, J.E.; J.H.TICKLE e Y.S.CHIN, 1968. Resistance to mercury of

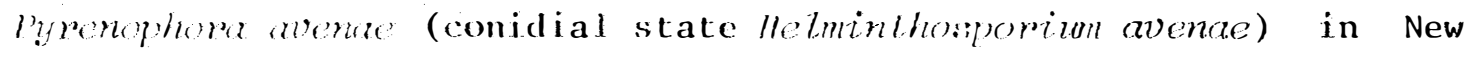
Zealand seed oats. New 'Lealand doumal of' Agriculture Research. We11ington, $11(3): 601-606$.

SZKOLNIK, M. e J.D.GILPATRICK, 1969. Apparent resistance of Venturia inaequalis to dodine in New York apple orchards. Plant disease Reporter. Washington, 53(11):861-864.

Ulssucil, Y., 1978. Resistance of phytopathop,enic fungi lo rungicides. elatian lis:tivide: Information. Tokyo, (35):5-9.

ULSUG1, Y.; M.KA'TAGIRI e O.NODA, 1974. Negatively correlated crossresistance and synergism between phosphoramidates and phosphorothiolates in their fungicidal actions on rice blast fungi. Agricultural and Biological Chemistry. Tokyo, 38(5):907-912.

WATANABE, T., 1971. Infectious drug resistance in bacteria. Current Topics in Microbiology and Immunology. Ber1in, 56:43-98.

WICKS, T., 1974. Tolerance of the apple scab fungus to benzimidazole fungicides. Plant Disease Reporter. Washington, 58(10):886-889.

WICKS, T., 1977. Tolerance to benzimidazole fungicides in blue mold (l'enioillium eaprasum) on pears. Plant biscass licporter. Washington, (j. $1(6): 447-449$.

WILD, B.L. e L.L.RIPPON, 1975. Response of penicillium digitatum strains to benomyl thiabendazole and sodium 0-phenylphenate. phytopathology. Lancaster, 65:1176-1177. 